\title{
Technical Change and the Commons
}

\author{
by \\ Dale Squires \\ U.S. National Marine Fisheries Service \\ 8604 La Jolla Shores Drive \\ La Jolla, California 92037 \\ Tel 858-546-7113 \\ Email dsquires@ucsd.edu \\ Niels Vestergaard \\ Department of Environmental and Business Economics \\ Centre for Fisheries \& Aquaculture Management \& Economics (FAME) \\ University of Southern Denmark \\ Emailnv@sam.sdu.dk
}

February, 2001

(Revised February 2009)

\begin{abstract}
This paper addresses the normative relationship between changes in technology and technical efficiency and the exploitation of common renewable resources. These changes can exacerbate the commons problem and deepen the externality. Their impact depends on the rate and nature of change, levels of effort and resource stock, and state of property rights. The paper develops an augmented fundamental equation of renewable resource economics with a modified marginal stock effect and a new marginal technology effect term that account for changes in technology and technical efficiency. Neglecting these changes generates misleading policy advice. An empirical application illustrates the results.
\end{abstract}

Key words: Technical change, common renewable resources, fundamental equation of renewable resources, economic efficiency

JEL Codes. O13, O33, Q22, Q28

Acknowledgements. The authors are grateful to David Au, John Childers, Paul Crone, and Pat Tomlinson for providing the biological parameters, advice on the population dynamics, and the U.S. catch and effort time series data used, to Jenny Sun and Ben Gilbert for econometric advice, to the American Fishermen's Research Foundation and the U.S. albacore troll industry for collecting the panel data, and John Holmes of the Department of Fisheries and Oceans Canada for the Canadian vessel data. The authors are grateful to workshop participants in Helsingor, Denmark, to seminar participants at Australian National University, La Trobe University, and University of Queensland, and to participants at the Vietnam meeting of the International Institute for Fisheries Economics and Trade (IIFET) for comments. The authors remain responsible for any errors. Squires is grateful to the University of Southern Denmark for support during a sabbatical. The results are not necessarily those of the U.S. National Marine Fisheries Service. 


\section{Introduction}

Technical progress and gains in economic efficiency are generally viewed as favorably contributing to economic growth and welfare, but does this normative conclusion hold for industries exploiting common renewable resources? What are their effects on the paradox between the individual firm's private economic efficiency and economic efficiency and social costs at the level of society with common renewable resources (Gordon 1954)? In short, what is the relationship between technical change and a broad notion of efficiency with the "Tragedy of the Commons" and the optimum exploitation of common renewable resources?

The normative economics literature on common renewable resources has largely overlooked technical change and its effects, instead focusing on steady-state levels of effort or capital stock, resource stock, yield, and their dynamic approaches under constant technology. ${ }^{1}$ Smith (1972), an exception, examined induced technological change and common renewable resources, finding that an unpriced common resource induces technical change in favor of increased utilization of the unpriced resource and that the competitive pressures of the race to fish can compel firms to adopt process innovations. Dasgupta (2008) recently reiterated these points and further discussed the relationship between technical change (and economic growth) and the shadow price of common renewable resources and other forms of natural capital and the role of property rights. Smith and Krutilla (1982) observed that technical change under open access accelerates the dissipation of resource rent and depletes resource stocks that are already overexploited. ${ }^{2}$ McAusland (2005) considered technical progress that directly affects the intrinsic growth rate of the resource stock but not the production technology, and was not concerned with direct normative economic optimization of resource exploitation. Murray (2007) introduced 
exogenous and disembodied technical progress into a static Gordon-Schaefer model of a fishery to show that not accounting for technological change can lead to overestimated natural growth of the resource stock and that inputs must be removed from the fishery at the rate of technological change to sustain the harvest target, and simulated the probability of resource stock collapse. In short, the normative literature has yet to formally analyze the impact of technical progress upon optimum exploitation of common renewable resources within a formal normative framework. This literature has considered non-autonomous models, but focused on exogenous price shocks (Clark 1990). This normative literature has similarly overlooked the notion of economic efficiency developed by Debreu (1951) and Farrell (1957), to instead concentrate solely on the efficient scale of production, i.e. on the optimum level of effort. ${ }^{3}$

In contrast, the normative exhaustible resource and sustainable growth literature has paid considerably more attention to technical progress and to substitution possibilities between the resource stock and inputs in discussions of natural resource scarcity, limits to growth, and backstop technologies (Arrow et al. 2004, Simpson et al. 2005). Farzin (1995), Berck (1995), and d'Autume and Schubert (2008) summarized the literature on technical progress and exhaustible resources and focused upon the impact of technical change on measures of resource scarcity. Climate change and the need to reduce fossil fuel and carbon emissions are focusing considerable attention upon induced technical change, with recent surveys by Jaffe, Newell, and Stavins (2003) and Pizer and Popp (2007).

This paper contributes to the normative economic literatures on technical change, efficiency, and optimum exploitation of renewable resources by introducing both output-oriented Debreu-Farrell technical inefficiency and technical progress into normative static and dynamic models of an industry exploiting a common renewable resource and examining the economic and 
policy ramifications. The paper develops the bioeconomic stages of production and clarifies that normative renewable resource models focus solely on scale efficiency and overlook technical and allocative efficiency. The most important contribution is an augmented fundamental equation of renewable resource economics that incorporates changes in technology and technical inefficiency into a new term, the marginal technology effect, and modifies the existing marginal stock effect. The results show that lower costs from technology generally outweigh lower costs from a higher resource stock and that resource stock levels can decline far below the steady-state equilibrium with static technology. The renewable resource model is developed for a fishery using the classic Gordon-Schaefer specification (Schaefer 1957, Gordon 1954), which lies at the heart of this literature and allows direct and analytic development of the modified Golden Rule. ${ }^{4}$ The technical change specified is disembodied, exogenous, and learning-by-doing and -using. ${ }^{5}$

Overlooking technical progress and technical efficiency in common renewable resource industries in a normative framework has profound policy consequences through exacerbating the commons problem under open access or potentially generating misleading policy advice in terms of economic optimum levels of the resource stock, yield, effort (input use), and economic welfare. In fishing industries, for example, once fish could no longer hide from vessels that are increasingly more technologically advanced, the stage was set for the current overfishing crisis in many of the world's fisheries. ${ }^{6}$ In fact, perhaps the single greatest pressure on global fisheries is technical progress, now that fishing fleets' capital stocks have built up to an overcapitalized state, but policy advice that remains focused solely on reducing capital stocks, fishing effort, or subsidies overlooks the ongoing march of technology that allows even reduced capital stock or effort to be more effective at finding and harvesting fish. Similarly, technical progress contributed mightily to the decimation of many of the great whale stocks (Davis et al. 1987). 
Section 2 develops a stochastic stock-flow production frontier incorporating technical change and technical inefficiency. Section 3 introduces this production frontier into the simple static Schaefer model that forms the basis of Section 4's static Gordon-Schaefer bioeconomic model, the workhorse of renewable resource economics, examining the Nash equilibrium of open access. Section 5 extends the Gordon-Schaefer rent frontier to the static steady-state Pareto optimum, i.e. the sole owner of Scott (1955). Section 6 develops the backward bending supply curve with technical progress and inefficiency based on the static Gordon-Schaefer rent frontier. Section 7 develops a simple normative dynamic model of the economic optimum incorporating technical inefficiency and technical change, culminating with an augmented Golden Rule or fundamental equation of renewable resources incorporating the new marginal technology effect term and a modified marginal stock effect. Section 8 considers several policies. Section 9 introduces the empirical application. The unavailability of detailed capital and investment data for the empirical example precludes an empirical analysis of embodied technical change. Section 10 provides the empirical results. Section 11 provides concluding remarks. The main static results are summarized in Table 1 for conditions with and without technical change or technical efficiency. Table 2 summarizes the main dynamic model results. All derivations in the paper are available in a separate Appendix from the authors.

\section{Fishery Production Frontier}

The stock-flow production function in time $t$ relates catch, $Y_{t}$, to the fish stock, $S_{t}$, and fishing effort, $E_{t}$ (Schaefer 1957): $Y_{t}=f\left(q, E_{t}, S_{t}\right){ }^{7}$ Catch is the output or flow from the resource stock, and the resource stock and fishing effort are specified as aggregate inputs. Effort is typically considered as the first stage in a two-stage production process and implicitly assumes 
weak or strong separability of $E_{t}$ from $S_{t}$ and $Y_{t}$, or Leontief aggregation, to form a composite index of inputs (Hannesson 1983, Squires 1987). The catchability coefficient, $q>0$, is the probability that one unit of effort taken at random will catch one unit of the population taken at random. $^{8}$ The classic bioeconomic model specifies a specific form of the Cobb-Douglas production function: $Y_{t}=q E_{t} S_{t}$, which has strong separability. A non-linear but positive exponent for the resource stock is possible depending on the nature of the fishery, giving $Y_{t}=q E_{t} S_{t}^{\beta}$, where $\beta=1$ implies evenly distributed fish and where schooling fish have lower positive values closer to zero (Hannesson 1993), as considered later in the paper.

Introducing time-varying output-oriented technical efficiency (TE) gives $Y_{t}=q S_{t} E_{t} e^{-\mu(t, Z)}$, where $-\mu(t, Z)$ denotes a nonpositive, half-sided error term that introduces deviations from the best-practice frontier or technical inefficiency. ${ }^{9}$ The measure for technical efficiency (TE) is $\exp \{-\mu(t, Z)\} \leq 1$. Technical inefficiency arises when $\mathrm{TE}<1$ and grows with increases in $\mu(t, Z)$. Technical inefficiency accounts for the time it may take for new technologies to attain their full productive potential and diffusion after their introduction, poorly designed regulation, the firm's managerial failure, and efficiency differences in harvesting units. The vector $Z$ could include policy variables $\Psi$ determined by the regulator that induce technical inefficiency or $\mathrm{Z}$ could include managerial (or crew) effort to allow for asymmetric information or different structures in incentives, such as alternative ownership structures or property rights.

Technical change, specified as exogenous, disembodied, and captured by a linear time trend $t$, can be introduced into the Graham-Schaefer surplus production frontier to give: ${ }^{10}$

$$
Y_{t}=q S_{t} E_{t} e^{\lambda t-\mu(t, Z)}
$$

The parameter $\lambda>(<) 0$ measures the rate of technical progress (regress), shifting the best-practice 
frontier, and $t$ denotes time. Technical change in (1) is necessarily Hick's-neutral with a single input, is output-augmenting (and equivalently input-augmenting with a composite input and linear homogeneity of the effort aggregator function), and could be easily specified to allow technical change which is non-neutral and which is not constant (through addition of interactions $E_{t} t, S_{t} t$, and $t^{2}$ to $e^{\lambda t}$ ); this is considered later in the paper, but initially for simplicity we retain the Hick's neutrality and constant rate. ${ }^{11}$ (Under open access, non-neutral technical change interacting with the resource stock should be biased toward resource-using, which accelerates the externality or commons problem as discussed by Smith (1972) and Ruttan (2001) and which we address later in the paper.) A more general index of autonomous technical change, $A(t)$, such as that of Baltagi and Griffin (1988), is easily substituted and is also employed in the empirical application, allowing technical change to vary in rate and direction in each time period, readily accommodates biases, and gives the specification of (1) as: $Y_{t}=q A(t) S_{t} E_{t} e^{-\mu(t, Z)} \cdot{ }^{12}$

Technical change in (1) can in part be viewed as a learning-by-doing and -using (Arrow 1962, Rosenberg 1982), once exogenous innovations have been introduced. ${ }^{13}$ Usually no formal $R \& D$ is devoted to technological advances except perhaps in all but the largest, most capitalintensive, and concentrated fishing industries. ${ }^{14}$ Firms adopt electronic and other process innovations for navigation, communication, finding fish, and monitoring gear performance while fishing (and under open access are compelled by the "race to fish"), followed by a period of learning (which can be captured by the technical inefficiency term). Some types of technical change (often regulatory induced) can mitigate the negative environmental externality of undersized fish or undesirable joint products (e.g. bycatch of turtles), but this paper focuses on technical change enabling production of desirable outputs at lower cost. Embodied technical 
change in the fishing vessel can also be important, but the focus here is on continuous and gradual smaller process innovations and subsequent learning related to finding fish, especially by the firm's manager (skipper) or learning by doing, and for discovery of new and unanticipated uses of the process innovations or learning by using by the manager and labor force (crew). Since industries exploiting renewable resources are largely mature, minimal depreciation of the largely tacit knowledge acquired through learning is anticipated (although little is known about the process by which this tacit knowledge is acquired). Normally, there is no opportunity cost other than the current cost of production with learning-by-doing (i.e. without other opportunity costs such as crowding out from $\mathrm{R} \& \mathrm{D}$ or knowledge market failures), but as demonstrated below, the external cost under incomplete property rights with common resources does create a social opportunity cost. There may also be learning benefit spillovers from one firm to the next, but the lion's share of the learning benefits are nonetheless expected to accrue to the firms engaged in the learning, especially to the skipper in finding fish (skippers usually own their vessels and intervessel skipper movement is usually limited) and to the crew in handling gear and equipment, although learning differences are anticipated among firms.

\section{The Schaefer Model: The Yield-Effort Frontier}

The equilibrium yield-effort function, developed by Schaefer (1957), starts with the net growth rate of the biomass specified as a simple differential equation: $d S_{t} / d t=F\left(S_{t}\right)-Y_{t}$, where $F\left(S_{t}\right)$ denotes a general growth function of the resource stock measured in biomass. Substituting (1) and the logistic or Pearl-Verhulst growth function ${ }^{15}$ into $d S_{t} / d t=F\left(S_{t}\right)-Y_{t}$ :

$$
\frac{d S_{t}}{d t}=r S_{t}\left[1-\frac{S_{t}}{K}\right]-q S_{t} E_{t} e^{\lambda t-\mu(t, Z)}
$$


where $\mathrm{r}$ is the maximum intrinsic growth rate of $S_{t}$, i.e. $r=\lim _{t \rightarrow 0}\left[\frac{d S_{t} / d t}{S_{t}}\right]$ and $\mathrm{K}$ is the carrying capacity, $\lim _{t \rightarrow \infty} S_{t}=K$ with zero harvest. In steady-state equilibrium, the instantaneous rate of change in the population is zero, i.e. $d S_{t} / d t=0 .^{16}$

Solving for the steady-state level of the biomass allowing for output-oriented technical inefficiency and technical progress gives for the Graham-Schaefer surplus production frontier:

$$
S^{T E, t}=K\left[1-\frac{q E_{t} e^{\lambda t-\mu(t, Z)}}{r}\right]
$$

The steady-state level of biomass, $S^{T E, t}$, depends not only upon r, K, q, and fishing effort, $\mathrm{E}_{\mathrm{t}}$, but now also on $e^{\lambda t-\mu(t, Z)}$. With continued technical progress we only have a steady-state equilibrium level of biomass if the fishing effort is reduced accordingly. This can be seen by differentiating (3) with respect to time (given the level of technical efficiency) to give:

$$
\frac{\partial S^{T E, t}}{\partial t}=-\frac{K}{r} q\left(E_{t} e^{\lambda t-\mu(t, Z)} \lambda+\frac{\partial E_{t}}{\partial t} e^{\lambda t-\mu(t, Z)}\right)
$$

From (4) it is clear that a steady-state equilibrium level of biomass requires $\partial E_{t} / \partial t=-\lambda E_{t}<0$. In other words if the level of fishing effort is constant, continuous technical progress will lower the level of the biomass. In principle, with a pure compensation population model, such as the logistic growth function and the static Schaefer model, the population can march inexorably to extinction with continued technical progress without corresponding reductions in the level of fishing effort, as illustrated by Figure 1 by the continued rotation upwards of the ray from the origin, the production frontier from Equation (1). ${ }^{17}$

The higher is technical efficiency, the lower is equilibrium level of $S^{T E, t}:^{18}$ 


$$
\frac{\partial S^{T E, t}}{\partial \mu(t, Z)}=\frac{K}{r} q E_{t} e^{\lambda t-\mu(t, Z)}>0
$$

This effect is shown in Figure 1 as an upwards shift of the production function. Changes in technical efficiency lead to changes in the steady-state equilibrium level of biomass.

[Figure 1 around here]

The equilibrium Schaefer yield-effort frontier allowing for technical inefficiency and technical change is found by substituting $S^{T E, t}$ from (3) into the production frontier (1) to give:

$$
Y_{t}^{T E, t}=q K E_{t} e^{\lambda t-\mu(t, Z)}\left[1-\frac{q E_{t} e^{\lambda t-\mu(t, Z)}}{r}\right]=q K E_{t} e^{\lambda t-\mu(t, Z)}-\frac{q^{2} K E_{t}^{2} e^{2 \lambda t-2 \mu(t, Z)}}{r} .
$$

The marginal product of effort, $M P_{E}^{T E, t}$, is $\partial Y^{T E, t} / \partial E_{t}=q K e^{\lambda t-\mu(t, Z)}-2 q^{2} K E_{t} e^{2 \lambda t-2 \mu(t, Z)} / r$. The average product of effort is $A P_{E}^{T E, t}=Y_{t}^{T E, t} / E_{t}=q K e^{\lambda t-\mu(t, Z)}-q^{2} K E_{t} e^{2 \lambda t-2 \mu(t, Z)} / r$ $=q K e^{\lambda t-\mu(t, Z)}\left\lfloor-q E_{t} e^{\lambda t-\mu(t, Z)} / r\right\rfloor$, or using (3), $A P_{E}^{T e, t}=q e^{\lambda t-\mu(t, Z)} S^{T E, t}$.

The level of technical efficiency of the fleet or the state of technical progress does not affect maximum sustainable yield (MSY) or the corresponding resource stock level (Figure 1). This follows because MSY and the stock level at MSY are solely determined by the biological parameters $r$ and K. However, the corresponding level of effort is affected. Differentiating (6) by $\mathrm{E}_{\mathrm{t}}$ and setting the result equal to zero gives the level of fishing effort that produces MSY (Table 1): $E_{M S Y}^{T E, t}=\frac{r}{2 q e^{\lambda t-\mu(t, Z)}}$. The difference $E_{M S Y}^{T E, t}-E_{M S Y}=\frac{r}{2 q}\left|\frac{1}{e^{\lambda t-\mu(t, Z)}}-1\right|$ indicates that technical progress reduces the effort and increases in technical inefficiency raise the effort yielding MSY, where $E_{M S Y}$ is the MSY level of effort in the standard model, i.e. without technical change and technical efficiency. Substituting $E_{M S Y}^{T E, t}$ into the yield-effort curve (6) gives MSY (Table 1): 
$Y_{M S Y}^{T E, t}=r K / 4$. Similarly, substituting $E_{M S Y}^{T E, t}$ into (3) gives $S_{M S Y}^{T E, t}=K / 2$. The difference $A P_{E}^{T E, t}-A P_{E}=q K\left[e^{\lambda t-\mu(t, Z)}-1\right]-q^{2} K E_{t}\left[e^{2 \lambda t-2 \mu(t, z)}+1\right]$ similarly indicates that technical progress reduces the average product of effort and that increase in technical inefficiency raises it.

Sustainable yield changes over time as given after differentiating (6) by time $t$ :

$$
\frac{\partial Y^{T E, t}}{\partial t}=q K E_{t} e^{\lambda t-\mu(t, Z)}\left[\lambda-\frac{\partial \mu(t, Z)}{\partial t}\right]-\left[\frac{q^{2} K E_{t}^{2} e^{2 \lambda t-2 \mu(t, Z)}}{r} 2\left[\lambda-\frac{\partial \mu(t, Z)}{\partial t}\right]\right]
$$

Technical progress holding technical inefficiency constant is given by:

$$
\frac{\partial Y^{T E, t}}{\partial t}=q K E_{t} e^{\lambda t-\mu(t, Z)} \lambda\left[1-\frac{2 q E_{t} e^{\lambda t-\mu(t, Z)}}{r}\right]=\lambda E_{t} M P_{E}^{T E, t} .
$$

The sustainable yield is zero when fishing effort exceeds the critical level of effort, $E_{c}$ (Clark 1976). In the standard equilibrium Schaefer yield-effort model, $E_{c}=r / q$; when $E>r / q$, the population is driven towards extinction and when $E \leq r / q=E_{c}$, there exists a stable equilibrium population level. When output-oriented technical efficiency and technical change are introduced into the equilibrium Schaefer yield-effort frontier (6), then $E_{c}^{T E, t}=r /\left[q e^{\lambda t-\mu(t, Z)}\right]$. The difference $E_{c}^{T E, t}-E_{c}=\frac{r}{q}\left[\frac{1}{e^{\lambda t-\mu(t, Z)}}-1\right]$ indicates that technical progress reduces the critical level of effort and technical inefficiency increases the critical level of effort.

The sign of $\partial Y^{T E, t} / \partial t$ depends on the level of E. Specifically, $\frac{\partial Y^{T E, t}}{\partial t}>(<) 0$ as $E_{t}<(>) r / 2 q e^{\lambda t-\mu(t, Z)}=E_{M S Y}^{T E, t}$, i.e. technical progress increases (decreases) equilibrium yield when $E_{t}<(>) E_{M S Y}^{T E, t}$. Technical progress raising equilibrium yield requires not only a positive rate of output augmentation, $\lambda>0$, but a positive marginal product of effort, $M P_{E}^{T E, t}>0$, or what is 
effectively harvesting in the Bioeconomic Stage II of Production where $0<E_{t}<E_{M S Y}^{T E, t} \cdot 19$

The marginal product of effort changes over time as given by:

$\left.\partial M P_{E}^{T E, t} / \partial t=\partial^{2} Y^{T E, t} / \partial E_{t} \partial t=[\lambda-\partial \mu(t, Z) / \partial t] g K e^{\lambda t-\mu(t, Z)}-4 q^{2} K E_{t} e^{2 \lambda t-2 \mu(t, Z)} / r\right]$. Holding

technical inefficiency constant, technical progress affects $M P_{E}^{T E, t}$ as:

$\left.\partial M P_{E}^{T E, t} / \partial t=\partial^{2} Y_{E}^{T E, t} / \partial E_{t} \partial t=\lambda \mid g K e^{\lambda t-\mu(t, Z)}-4 q^{2} K E_{t} e^{2 \lambda t-2 \mu(t, Z)} / r\right\rfloor$

$=\lambda q K e^{\lambda t-\mu(t, Z)}\left[1-4 q K E_{t} e^{\lambda t-\mu(t, Z)} / r\right\rfloor . \partial M P_{E}^{T E, t} / \partial t>(<) 0$ when $E_{t}<(>) E_{M S Y}^{T E . t} / 2$, as indicated by

setting the terms inside the bracket equal to zero and solving for E, giving

$E_{t}=r / 4 q E_{t} e^{\lambda t-\mu(t, Z)}=E_{M S Y}^{T E, t} / 2$. Changes in technical inefficiency on $M P_{E}^{T E, t}$ holding technical

progress constant are given by $\partial M P_{E}^{T E, t} / \partial t=\partial^{2} Y^{T E, t} / \partial E_{t} \partial \mu(t, Z)=$

$-\partial \mu(t, Z) / \partial t\left[g K e^{\lambda t-\mu(t, Z)}-4 q^{2} K E_{t} e^{2 \lambda t-2 \mu(t, Z)} / r\right]=-\mu(t, Z) q K e^{\lambda t-\mu(t, Z)}\left[1-4 q K E_{t} e^{\lambda t-\mu(t, Z)} / r\right]$.

$\partial M P_{E}^{T E, t} / \partial \mu(t, z)(<) 0$ as $E_{t}<(>) E_{M S Y}^{T E . t} / 2$. Figure 2 illustrates the effect of technical progress on $M P_{E}^{T E, t}$.

[Figure 2 around here]

The average product of effort changes over time as given by:

$\left.\partial A P_{E}^{T E, t} / \partial t=[\lambda-\partial \mu(t, Z) / \partial t] \mid g K e^{\lambda t-\mu(t, Z)}-2 q^{2} K E_{t} e^{2 \lambda t-2 \mu(t, Z)} / r\right]$. Holding technical inefficiency constant, setting the terms inside the brackets equal, and solving shows that $\partial A P_{E}^{T E, t} / \partial t>(<) 0$ as $E_{t}<(>) E_{M S Y}^{T E, t}$

The effect of the level of technical inefficiency on sustainable yield depends on the level of effort vis-à-vis the MSY level of effort, $E_{M S Y}^{T E, t}$, or equivalently, the resource stock vis-à-vis MSY, $S_{M S Y}^{T E, t}$. Holding technical progress constant, differentiating the equilibrium yield-effort 
frontier, Equation (6), with respect to $\mu(t, Z)$ gives:

$$
\frac{d Y^{T E, t}}{d \mu(t, Z)}=q K E_{t} e^{\lambda t-\mu(t, Z)}\left[-1+\frac{2 q E_{t} e^{\lambda t-\mu(t, Z)}}{r}\right] .
$$

The sign of $d Y^{T E, t} / d \mu(t, Z)$ depends on the algebraic sign of $\left\lfloor-r+2 q E_{t} e^{\lambda t-\mu(t, Z)}\right\rfloor$ which since $q K E_{t} e^{\lambda t-\mu(t, Z)}>0$, depends on the level of effort E vis-à-vis $E_{M S Y}^{T E, t}$. Hence, when $E_{t}>(<) \frac{r}{2 q e^{\lambda t-\mu(t, Z)}}=E_{M S Y}^{T E, t}, d Y^{T E, t} / d \mu(t, Z)>(<) 0$, i.e. when $E_{t}>(<) E_{M S Y}^{T E, t}$ an increase in technical inefficiency or reduction in technical efficiency leads to an increase (decrease) in sustainable yield. Similar to technical progress, $\partial M P_{E}^{T E, t} / \partial \mu(t, Z)<(>) 0$, as $E_{t}<(>) E_{M S Y}^{T E . t} / 2$.

In short, changes in technical efficiency and technology can raise (lower) sustainable, steady-state yield at lower (higher) levels of effort than that of MSY, at which point the resource stock is comparatively higher (lower) and the marginal product of effort is positive (negative). ${ }^{20}$ These results with a renewable resource and the requirement of sustainable yield sharply contrast with the usual expected result in industries that do not exploit a renewable resource with a stockflow technology in which an increase in technical efficiency (up to the frontier) and especially technology raises output levels regardless of the input levels. This can also been seen in Figure 1. If the surplus production frontier crosses the growth function below $S_{M S Y}$, then increases in effort decreases equilibrium yield, while if the surplus production frontier crosses above $S_{M S Y}$, then increases in effort increase equilibrium yield.

The traditional static results are now conditional upon the level of technical inefficiency and the state of technology. Allowing for technical inefficiency and technical progress shows that there any number of sustainable equilibria effort, resource stock, and catch levels, and that these 
sustainable equilibria can readily change over time through technical progress and changes in technical efficiency. Increases in technical efficiency and technical progress raise sustainable yields at levels of effort below the $E_{M S Y}^{T E, t}$, i.e. at a Bioeconomic Stage II of Production, but lower sustainable yields at higher effort levels. Increases in technical efficiency and technical progress raise $M P_{E}^{T E, t}$ at levels of effort one-half of $E_{M S Y}^{T E, t}$. In both instances, $E_{M S Y}^{T E, t}$ is declining with increases in technical efficiency and technical progress and hence the interval of effort within the bioeconomic Stage II of Production will continue to decrease.

\section{The Gordon-Schaefer Bioeconomic Model}

Gordon (1954) developed the classic static bioeconomic model based on the equilibrium Schaefer yield-effort curve when the access to the fishery is open. Let $\mathrm{P}=$ constant price per unit of harvested biomass (yield). Let $\mathrm{c}=$ constant (marginal and average) cost per unit of effort, where allow all costs to be variable in a given time period. Total sustainable revenue (using Equation 6) is $T R^{T E, t}=P q K E_{t} e^{\lambda_{t}-\mu(t, Z)}\left[1-\frac{q E_{t} e^{\lambda t-\mu(t, Z)}}{r}\right]$. Total cost is commonly specified $T C=c E_{t}$, so that the costs of fishing are proportional to the effort expended.

The rent frontier allowing for technical inefficiency and technical change is:

$$
\begin{gathered}
\pi\left[P, c, r, q, K, E, e^{\lambda t-\mu(t, Z)}\right]=T R^{T E, t}-T C^{T E, t}=P q K E_{t} e^{\lambda t-\mu(t, Z)}\left[1-\frac{q E_{t} e^{\lambda t-\mu(t, Z)}}{r}\right]-c E_{t} \\
=P q K E_{t} e^{\lambda t-\mu(t, Z)}-\left[\frac{P q^{2} K E_{t}^{2} e^{2 \lambda t-2 \mu(t, Z)}}{r}\right]-c E_{t} .
\end{gathered}
$$

The marginal revenue of effort from (10) is: $\partial T R^{T E, t} / \partial E=M R_{E}^{T E, t}$

$$
=\partial\left\lfloor P q K E_{t} e^{\lambda_{t}-\mu(t, Z)}-P q^{2} K E_{t}^{2} e^{2(\lambda t-\mu(t, Z)} / r\right\rfloor \partial E=P q K e^{\lambda t-\mu(t, Z)}-2 P q^{2} K E_{t} e^{2 \lambda t-2 \mu(t, Z)} / r=
$$


$=P q K e^{\lambda t-\mu(t, Z)}\left[1-2 \frac{q E_{t} e^{\lambda t-\mu(t, Z)}}{r}\right] \cdot M R_{E}^{T E, t}>(<) 0$ depends on $E_{t}<(>) E_{M S Y}^{T E, t}$. Setting the two terms inside the brackets equal to zero and solving for E shows that $M R_{E}^{T E, t}>(<) 0$ as $E_{t}<(>) r /\left[2 q e^{\lambda t-\mu(t, Z)}\right]=E_{M S Y}^{T E, t}$, that is, within a Bioeconomic Stage II of Production.

Technical progress changes $M R_{E}^{T E, t}$ by output-augmentation in the production frontier (1), and thus the Schaefer yield-effort frontier (6), and is given by:

$$
\frac{\partial M R_{E}^{T E, t}}{\partial t}=\left[\lambda-\frac{\partial \mu(t, Z)}{\partial t}\right] P q K e^{\lambda t-\mu(t, Z)}\left[1-\frac{4 q E_{t} e^{\lambda t-\mu(t, Z)}}{r}\right]
$$

Setting the terms inside the right-hand bracket equal to zero, holding technical inefficiency constant, and solving for $E^{T E, t}$ gives: $E^{T E, t}=r / 4 q e^{\lambda t-\mu(t, Z)}=E_{M S Y}^{T E, t} / 2$, where $E_{M S Y}^{T E, t}$ corresponds to prior technical progress. Hence, since $\lambda P q K e^{\lambda t-\mu(t, Z)}>(<) 0$ for technical progress (regress), $\partial M R_{E}^{T E, t} / \partial t>(<) 0$ as $E^{T E, t}<(>) E_{M S Y}^{T E, t} / 2$. Technical progress increases $M R_{E}^{T E, t}$ over increasingly lower levels of effort as time progresses as illustrated in Figure 2, recognizing that $M R_{E}^{T E, t}=P M P_{E}^{T E, t}$

A different specification of the rent frontier is found by solving the production frontier (1) for $E_{t}=\left\lfloor Y / q S e^{\lambda t-\mu(t, Z)}\right]$, and substituting into the cost equation $T C=c E_{t}$ to give the cost function:

$$
T C[Y, S, q, \lambda,-\mu(t, Z)]=\frac{c}{e^{\lambda t-\mu(t, Z)}} \frac{Y_{t}}{q S_{t}} .
$$

Technical progress leads to cost diminution, where the TC function can now be interpreted in terms of input price diminishment or effective input price, given by $c / \phi(t)$, and where $\phi(t)=e^{\lambda t-\mu(t, Z)}$ is the augmentation coefficient. ${ }^{21}$ With a single composite input, cost-reducing 
technical change can be viewed as cost-neutral and is equivalent to rent-neutral and Hick'sneutral technical change with the homogenous Gordon-Schaefer rent frontier. ${ }^{22}$

Technical progress and gains in technical efficiency reduce costs. From $\partial T C^{T E, t} / \partial t=-[\lambda-\partial \mu(T, Z) / \partial t]\left[c Y_{t} / e^{\lambda t-\mu(t, Z)} q S_{t}\right]$ and holding technical inefficiency constant, $\partial T C^{T E, t} / \partial t=-\lambda\left\lfloor Y_{t} / e^{\lambda t-\mu(t, Z)} q S_{t}\right\rfloor<0$, i.e. cost diminution, and holding technical change constant gives $\partial T C^{T E, t} / \partial t=\partial \mu(t, Z) / \partial t\left\lfloor c Y_{t} / e^{\lambda t-\mu(t, Z)} q S_{t}\right\rfloor>0$, i.e. increases in technical efficiency also diminishes cost. Increases (decreases) in the resource stock lower (raise) total costs, $\partial T C^{T E, t} / \partial S=-c Y_{t} / \mathbf{e}^{\lambda t-\mu(t, Z)} q S_{t}^{2} k 0$, and decreases in the resource stock combined with technical progress raise total costs, $\left.\partial^{2} T C^{T E, t} / \partial S \partial t=\lambda c Y_{t} / e^{\lambda t-\mu(t, Z)} q S_{t}^{2}\right\rfloor>0$, as might be expected as technical progress reduces the resource stock, thereby countervailing the effect of technical progress on costs. ${ }^{23}$ Marginal cost is given by $\left.M C_{E}^{T E, t}=\partial T C^{T E, t} / \partial Y=c / e^{\lambda t-\mu(t, Z)} q S_{t}\right\rfloor$, and increases in technology, technical efficiency, and resource stock have the same effect on marginal cost as on total cost, i.e. $\partial^{2} T C^{T E, t} / \partial Y \partial t<0, \partial^{2} T C^{T E, t} / \partial Y \partial \mu(t, z)>0$ and $\partial^{2} T C^{T E, t} / \partial Y \partial S<0$

The rent frontier using the cost function is written:

$$
\pi\left[P, c, q, S, Y, e^{\lambda t-\mu(t, Z)}\right]=P Y_{t}-\frac{c}{e^{\lambda t-\mu(t, Z)}} \frac{Y_{t}}{q S_{t}}=\left[P-\frac{c}{q S_{t} e^{\lambda t-\mu(t, Z)}}\right] Y_{t} .
$$

This rent frontier in terms of yield and biomass is used in several derivations below and in the dynamic model. The rent frontier in terms of effort, Equation (10), is useful for empirical analysis of time series of catch and effort.

Sustainable resource $\pi^{T E, t}$ rent changes over time in (10) according to: 


$$
\begin{aligned}
\frac{\partial \pi^{T E, t}}{\partial t} & =\left[\lambda-\frac{\partial \mu(t, Z)}{\partial t}\right]\left[P q K E_{t} e^{\lambda t-\mu(t, Z)}-\frac{2 P q^{2} K E_{t} e^{\lambda t-\mu(t, Z)}}{r} E_{t} e^{\lambda t-\mu(t, Z)}\right] \\
& =\left[\lambda-\frac{\partial \mu(t, Z)}{\partial t}\right] M R_{E}^{T E, t} E_{t} .
\end{aligned}
$$

Holding constant changes in technical inefficiency over time gives the effects of technical progress on resource rent:

$$
\frac{\partial \pi^{T E, t}}{\partial t}=\lambda E_{t}\left[P q K e^{\lambda t-\mu(t, Z)}-\frac{2 P q^{2} K E_{t} e^{2 \lambda t-2 \mu(t, Z)}}{r}\right]=\lambda M R_{E}^{T E, t} E_{t} .
$$

Given $\lambda, E_{t}>0$, the sign of $\partial \pi^{T E, t} / \partial t$ depends on the sign of $M R_{E}^{T E, t}$, which in turn depends on the sign of the terms in the bracket. Setting the terms inside the brackets equal to zero and solving gives $r / 2 q e^{\lambda t-\mu(t, Z)}=E_{t}$ or $E_{M S Y}^{T E, t}=E_{t} . \partial \pi^{T E, t} / \partial t=\lambda E_{t} M R_{E}^{T E, t}>(<) 0$ when $M R_{E}^{T E, t}>(<) 0$, which occurs when $E_{t}<(>) E_{M S Y}^{T E, t}$, i.e. when effort falls within the Bioeconomic Stage II of production, which also corresponds to $S_{t}>(<) S_{M S Y} \cdot{ }^{24}$ We observe in passing that the technical progress raises rent (11) through reductions in total costs and that $\left.\partial \pi^{T E, t} / \partial t=\lambda c Y_{t} / e^{\lambda_{t}-\mu(t, Z)} q S_{t}\right\rfloor>0$. Much traditional regulation limits production or input use and thereby creates technical inefficiency. The effect of an increase in technical inefficiency on resource rent is given by:

$$
\frac{\partial \pi^{T E, t}}{\partial \mu(t, Z)}=-\mu(t, Z) E_{t}\left[P q K e^{\lambda t-\mu(t, Z)}-\frac{2 P q^{2} K E_{t} e^{2 \lambda t-2 \mu(t, Z)}}{r}\right]=-\mu(t, Z) M R_{E}^{T E, t} E_{t}
$$

The effect of regulation by technical inefficiency is captured by $\frac{\partial \pi^{T E, t}}{\partial \mu(t, Z)} \frac{\partial \mu(t, Z)}{\partial Z}$. Similar to technical change, given $-\mu(t, Z)<0$ and $E>0, \partial \pi^{T E, t} / \partial \mu(t, Z)=-\mu(t, Z) M R_{E}^{T E, t} E_{t}<(>) 0$, when $M R_{E}^{T E, t}>(<) 0$, which occurs when $E_{t}<(>) E_{M S Y}^{T E, t}$, which corresponds to $S_{t}>(<) S_{M S Y}$ and the 
Bioeconomic Stage II of production.

\subsection{The Gordon-Schaefer Model under Open Access}

At the open-access equilibrium, all rents are dissipated, so that

$\pi\left[P, c, r, q, K, E_{t} \cdot e^{\lambda t-\mu(t, Z)}\right]=0$ and the level of effort is larger than Pareto-optimal. Solving for the steady-state equilibrium level of biomass under open access, $S_{\infty}^{T E, t}$, from (11) gives:

$$
S_{\infty}^{T E, t}=\frac{c}{P q e^{\lambda t-\mu(t, Z)}}
$$


$S_{\infty}=c / P q$ in the standard Gordon model without technical efficiency and the state of technology and is constant over time. The level of technical efficiency, the state of technology, catchability, and the cost-price ratio determine $S_{\infty}^{T E, t}$ in (15). The difference $S_{\infty}^{T E, t}-S_{\infty}=\frac{c}{P q}\left\lfloor\frac{1}{e^{\lambda t-\mu(t, Z)}}-1\right\rfloor$ indicates that technical progress and increases in technical efficiency reduce $S_{\infty}^{T E, t}$, i.e. $S_{\infty}^{T E, t}<S_{\infty}$.

Technical progress reduces the steady-state resource stock over all population levels with pure compensation models such as the logistic. Differentiating (15) by $t$ gives:

$$
\frac{\partial S_{\infty}^{T E, t}}{\partial t}=\frac{c}{P q e^{\lambda t-\mu(t, Z)}}\left[-\lambda+\frac{\partial \mu(t, Z)}{\partial t}\right]=-S_{\infty}^{T E, t}\left[\lambda-\frac{\partial \mu(t, Z)}{\partial t}\right] .
$$

Holding technical inefficiency constant shows that continued technical progress leads to inexorable decline in the resource stock:

$$
\frac{\partial S_{\infty}^{T E, t}}{\partial t}=\frac{-\lambda c}{P q e^{\lambda t-\mu(t, Z)}}=-\lambda S_{\infty}^{T E, t}<0 .
$$

The inherent inability of input controls to halt this decline in the face of continued technical progress and ill-structured property rights is evident. Technical progress creates a paradox, in which gains in private efficiency through process innovations reduce the resource stock for all.

Regulation by increasing technical inefficiency lifts the open-access equilibrium resource stock, demonstrating the paradox. Differentiating (15) by $\mu(t, Z)$ gives:

$$
\frac{\partial S_{\infty}^{T E, t}}{\partial \mu(t, Z)}=\mu(t, Z) \frac{c}{P q e^{\lambda t-\mu(t, Z)}}=\mu(t, Z) S_{\infty}^{T E, t}>0
$$


Because technical efficiency only increases to the best-practice frontier that exists in a given time period, there is an inherent limit to the extent that gains in technical efficiency can drive down the resource stock. Technical progress is clearly the more powerful force for resource stock declines.

The open-access level of effort, $E_{\infty}^{T E, t}$, allowing for technical efficiency, the state of technology, and steady-state equilibrium is found by setting $\pi=0$ in (10) to give:

$$
E_{\infty}^{T E, t}=\frac{r}{q e^{\lambda t-\mu(t, Z)}}\left[1-\frac{c}{P K q e^{\lambda t-\mu(t, Z)}}\right]=\eta\left[\frac{P q K e^{2 \lambda t-2 \mu(t, Z)}-c}{P q^{2} K e^{2 \lambda t-2 \mu(t, Z)}}\right]
$$

(19a)

$$
=\frac{r}{q e^{\lambda t-\mu(t, Z)}}\left[1-\frac{S_{\infty}^{T E, t}}{K}\right]=2 E_{M S Y}^{T E, t}\left[1-\frac{S_{\infty}^{T E, t}}{K}\right] .
$$

In the standard model $E_{\infty}=r\left\lfloor\frac{P q K-c}{P q^{2} K}\right\rfloor=\frac{r}{q}\left[1-\frac{c}{p q K}\right]$. and the difference is $E_{\infty}^{T E, t}-E_{\infty}=\frac{r}{P q^{2} K}\left[[P q K+c]\left[\frac{1}{e^{\lambda t-\mu(t, Z)}}-1\right]\right] . E_{\infty}^{T E, t}<(>) E_{\infty}$ depending on the relative strengths of technical progress and technical inefficiency, but where $E_{\infty}^{T E, t}<E_{\infty}$ with technical progress and increases in technical efficiency.

Changes in technology and technical efficiency alter $E_{\infty}^{T E, t}$. Differentiating (19a)

by $t$ :

$$
\left.\left.\frac{\partial E_{\infty}^{T E, t}}{\partial t}=\frac{r}{q e^{\lambda t-\mu(t, Z)}}\left[1-\frac{2 c}{P q K e^{\lambda t-\mu(t, Z)}}\right]-\lambda+\frac{\partial \mu(t, Z)}{\partial t}\right]=-\frac{r}{q e^{\lambda t-\mu(t, Z)}}\left[1-\frac{S_{\infty}^{T E, t}}{K / 2}\right] \lambda-\frac{\partial \mu(t, Z)}{\partial t}\right] .
$$


Holding technical inefficiency constant, (20) reduces to the effects of technical progress on $E_{\infty}^{T E, t}$ :

$$
\frac{\partial E_{\infty}^{T E, t}}{\partial t}=-\frac{\lambda r}{q e^{\lambda t-\mu(t, Z)}}\left[1-\frac{2 c}{P q K e^{\lambda t-\mu(t, Z)}}\right]=-\frac{\lambda r}{q e^{\lambda t-\mu(t, Z)}}\left[1-\frac{S_{\infty}^{T E, t}}{K / 2}\right]=-\lambda E_{M S Y}^{T E, t}\left[1-\frac{S_{\infty}^{T E, t}}{S_{M S Y}}\right] .
$$

The effect of technical progress on $E_{\infty}^{T E, t}$ depends on the level of $S_{\infty}^{T E, t}$ relative to $S_{M S Y}=S_{M S Y}^{T E, t}=K / 2$, because $-\lambda r / q e^{\lambda t-\mu(t, Z)}=-\lambda 2 E_{M S Y}^{T E, t}<0$. Setting the terms inside of the brackets equal to zero and solving gives $S_{\infty}^{T E, t}=K / 2=S_{M S Y}$, so that $\partial E_{\infty}^{T E, t} / \partial t<(>) 0$ as $S_{\infty}^{T E, t}<(>) S_{M S Y}$. Technical progress lowers (raises) effort in open access if the open access resource stock is less (greater) than the MSY stock level. The resource stock under open access can generally be expected to lie below $S_{M S Y}$, so that technical progress can be expected to lower effort.

Figure 3 illustrates the effect of technical progress on the sustainable revenue frontier, total costs, and effort. Technical progress shifts the revenue frontier toward the origin and reduces the open-access level of effort.

[Figure 3 around here]

The effects of changes in technical inefficiency on $E_{\infty}^{T E, t}$ depend on the level of $S_{\infty}^{T E, t}$ relative to $S_{M S Y}$. Differentiating $(19 \mathrm{~b})$ by $\mu(t, Z)$ gives:

$$
\frac{\partial E_{\infty}^{T E, t}}{\partial \mu(t, Z)}=\frac{\mu(t, Z) r}{q e^{\lambda t-\mu(t, Z)}}\left[1-\frac{S_{\infty}^{T E, t}}{K / 2}\right]=\mu(t, Z) \frac{E_{M S Y}^{T E}}{2}\left[1-\frac{S_{\infty}^{T E, t}}{S_{M S Y}}\right] .
$$

$\mu(t, Z) r / q e^{\lambda t-\mu(t, Z)}>0$. Setting the terms inside of the brackets equal to zero and solving gives $S_{\infty}^{T E, t}=K / 2=S_{M S Y}$, the resource stock level at which $E_{\infty}^{T E, t}=E_{M S Y}$ also occurs, so 
that: $\partial E_{\infty}^{T E, t} / \partial \mu(t, Z)>(<) 0$ as $S_{\infty}^{T E, t}<(>) S_{M S Y}$.

In short, gains in private technical efficiency and technical progress pose a social problem with open access or unregulated common property through short run rises in catch rates, increases in effort, a new Pareto-inefficient equilibrium, and further reductions of the resource stock (which is socially undesirable if this level is less than the target). These gains in private technical efficiency and technical progress raise social costs as the technological resource stock externality is exacerbated, as is demonstrated next.

\subsection{The Resource Stock Externality under Open Access}

The effect of technical inefficiency and technical progress on the technological resource stock externality under open access can be examined with a simple static model adapted from Hartwick and Olewiler (1998). Letting $P=1$, the average revenue of effort $\left(A R_{E}^{T E, t}\right)$ equals the average product of effort $\left(A P_{E}^{T E, t}\right)$ and $M R_{E}^{T E, t}=M P_{E}^{T E, t}$. The total harvest from the fishery is $Y_{E}^{T E, t}=A P_{E}^{T E, t} E_{t}$. Differentiating $Y_{E}^{T E, t}=A P_{E}^{T E, t} E_{t}$ with respect to E gives: $M P_{E}^{T E, t}=\frac{d Y_{E}^{T E, t}}{d E}=A P_{E}^{T E, t}+E_{t} \frac{d A P_{E}^{T E, t}}{d E}$, where $E_{t} \frac{d A P_{E}^{T E, t}}{d E}$ is the stock effect or the technological stock externality.

The stock effect is negative, $M P_{E}^{T E, t}-A P_{E}^{T E, t}=-\frac{q^{2} K E_{t} e^{2 \lambda t-2 \mu(t, Z)}}{r}<0$, because an increase in E reduces the sustainable resource stock, which in turn lowers the catch per unit of effort, $A P_{E}^{T E, t}$. For each increment in $\mathrm{E}$, firms actually receive the industry $A P_{E}^{T E, t}$ minus the stock effect, which no firm considers. All firms in the industry are affected by the marginal change in $\mathrm{E}$, but because the effect per firm is relatively small, each firm ignores it. 
The size of the externality depends upon the level of effort and the state of technology and technical efficiency. The stock externality changes over time according to:

$$
\frac{\partial\left[M P_{E}^{T E, t}-A P_{E}^{T E, t}\right]}{\partial t}=\frac{\partial}{\partial t}\left[-\frac{q^{2} K E_{t} e^{2 \lambda t-2 \mu(t, Z)}}{r}\right]=\frac{-2 q^{2} K E_{t} e^{2 \lambda t-2 \mu(t, Z)}}{r}\left[\lambda-\frac{\partial \mu(t, Z)}{\partial t}\right]
$$

Holding technical inefficiency constant, $\partial\left[M P_{E}^{T E, t}-A P_{E}^{T E, t}\right] / \partial t$ gives the impact of technical progress on the stock externality. Because $\left[-2 \lambda q^{2} K E_{t} e^{2 \lambda t-2 \mu(t, Z)}\right\rfloor_{r}<0$, technical progress deepens the stock externality, widening the wedge between the private and social costs. Even though the technical progress exacerbates the stock externality, adversely impacting all firms in the fishery and indeed society as a whole, each firm ignores this growing adverse marginal impact because the effect per firm is small and because the firm instead receives the average product less the small stock effect.

The effect of a change in technical efficiency on the stock externality is:

$$
\frac{\partial\left[M P_{E}^{T E, t}-A P_{E}^{T E, t}\right]}{\partial-\mu(t, Z)}=\frac{\partial}{\partial-\mu(t, Z)}\left[-\frac{q^{2} K E_{t} e^{2 \lambda t-2 \mu(t, Z)}}{r}\right]=\frac{-2 q^{2} K E_{t} e^{2 \lambda t-2 \mu(t, Z)}}{r}<0
$$

Declines in technical inefficiency through time similarly exacerbate the stock externality.

\section{The Static Pareto Optimum: The Sole Owner}

The "sole owner" provides the standard static Pareto-optimum benchmark to the inefficient open-access equilibrium (Scott 1955). The sole owner might be an individual firm or public agency maximizing social welfare. The Pareto optimum is now comprised of both scale and technical efficiency and is conditional upon the state of technology. The 
static rent-maximizing sole owner with output-oriented technical inefficiency and technical progress maximizes the rent frontier $\pi\left[P, c, E_{t}, r, q, t, \mu\right]=P Y\left[E_{t}, r, q, t, \mu\right]-c E_{t}$, Equation $(10) .{ }^{25}$ The first-order condition for rent maximization and a Pareto optimum is: ${ }^{26}$

$$
\frac{\partial \pi^{T E, t}}{\partial E}=P q K e^{\lambda t-\mu(t, Z)}-\frac{2 P q^{2} K E_{t} e^{2 \lambda t-2 \mu(t, Z)}}{r}-c=0
$$

Scale efficiency, given technical inefficiency and the state of technology, occurs when

$$
M R_{E}^{T E, t}=M C_{E} \text {, i.e. } P q K e^{\lambda t-\mu(t, Z)}-\frac{2 P q^{2} K E_{t} e^{2 \lambda t-2 \mu(t, Z)}}{r}=c,
$$

where the Pareto optimum requires full technical efficiency.

The level of fishing effort giving scale efficiency with technical progress and technical inefficiency is:

$$
E_{*}^{T E, t}=\frac{r\left[P q K e^{\lambda t-\mu(t, Z)}-c\right]}{2 P q^{2} K e^{2 \lambda t-2 \mu(t, Z)}}=\frac{r}{2 q e^{\lambda t-\mu(t, Z)}}\left[1-\frac{S_{\infty}^{T E, t}}{K}\right]=E_{M S Y}^{T E, t}\left[1-\frac{S_{\infty}^{T E, t}}{K}\right] .
$$

As with the standard sole owner model, and comparing (19b) with (26), $E_{*}^{T E, t}=E_{\infty}^{T E, t} / 2$, but the technical inefficiency leads to lower levels of both open-access equilibrium and optimal level of effort than under full technical efficiency. That is, the efficient scale of production for the aggregate technology requires lower effort. Figure 3 illustrates the optimal effort prior to technical progress, $E_{*}$, and the reduction in optimal effort from technical progress, $E_{*}^{T E, t}$.

In the standard model, $E_{*}=r[P q K-c] / 2 P q^{2} K$, and the difference is 
$E_{*}^{T E, t}-E_{*}=\frac{r\left[P q K e^{\lambda t-\mu(t, Z)}-c\right]}{2 P q^{2} K e^{2 \lambda t-2 \mu(t, Z)}}-\frac{r[P q K-c]}{2 P q^{2} K}=\frac{r}{2 P q^{2} K}\left[[P q K+c]\left[\frac{1}{e^{\lambda t-\mu(t, Z)}}-1\right]\right]$.

$E_{*}^{T E, t}<(>) E_{*}$, depending on the relative strengths of technical progress and technical inefficiency, but with technical progress and increases in technical efficiency $E_{*}^{T E, t}<E_{*}$.

The effects of changes in technology and technical inefficiency on the Paretooptimum level of effort are the same as on the open-access level of effort, since $E_{*}^{T E, t}=E_{\infty}^{T E, t} / 2$, i.e. since $E_{*}^{T E, t}$ is simply a scalar multiple of $E_{\infty}^{T E, t}$, see Equation 20.

Thus, $\frac{\partial E_{*}^{T E, t}}{\partial t}=\frac{\partial E_{\infty}^{T E, t} / 2}{\partial t}=-\frac{1}{2} \lambda E_{M S Y}^{T E, t}\left[1-\frac{S_{\infty}^{T E, t}}{S_{M S Y}}\right]$ and the same conclusions hold as with $\partial E_{\infty}^{T E, t} / \partial t$

The static scale-efficient level of the resource stock $S_{*}^{T E, t}$ is:

$$
S_{*}^{T E, t}=K-\frac{K}{2}\left\lfloor 1-\frac{c}{P q K e^{\lambda t-\mu(t, Z)}}\right\rfloor=\frac{1}{2}\left[K+S_{\infty}^{T E, t}\right],
$$

where the Pareto optimum requires full technical efficiency.

The level of carrying capacity, technical efficiency, the state of technology, catchability, and the cost-price ratio determine $S_{*}^{T E, t}$ in (27). It follows from equation (27) that the sole owner resource stock is larger than the open-access resource stock, i.e. $S_{*}^{T E, t}>S_{\infty}^{T E, t}$. The optimal stock level in the standard model is $S_{*}=\frac{K}{2}\left(1+\frac{c}{p q K}\right)$ and the difference $S_{*}^{T E, t}-S_{*}=\frac{c}{P q}\left[\frac{1}{e^{\lambda t-\mu(t, Z)}}-1\right]$ indicates that technical progress and increases in technical efficiency reduce $S_{*}^{T E, t}$, i.e. $S_{*}^{T E, t}<S_{*}$.

The Pareto-optimal stock $S_{*}^{T E, t}$ changes over time according to: 


$$
\frac{\partial S_{*}^{T E, t}}{\partial t}=\frac{\partial}{\partial t} \frac{1}{2}\left[K+S_{\infty}^{T E, t}\right]=\frac{\partial\left[S_{\infty}^{T E, t} / 2\right]}{\partial t}=\frac{\partial}{\partial t}\left[\frac{c}{2 P q e^{\lambda t-\mu(t, Z)}}\right]=-\left[\lambda-\frac{\partial \mu(t, Z)}{\partial t}\right] \frac{S_{\infty}^{T E, t}}{2} .
$$

Holding technical inefficiency constant, technical progress lowers $S_{*}^{T E, t}$ :

$$
\frac{\partial S_{*}^{T E, t}}{\partial t}=-\lambda \frac{S_{\infty}^{T E, t}}{2}<0
$$

Increases in technical inefficiency given technology raise $S_{*}^{T E, t}$ :

$$
\frac{\partial S_{*}^{T E, t}}{\partial \mu(t, Z)}=\mu(t, Z) \frac{S_{\infty}^{T E, t}}{2}>0
$$

which reaches the scale- and technically efficient optimum when $\mathrm{TE}=1$.

Under open access, the regulator may invoke the policy variables $\Psi$ to induce technical inefficiency and thereby guide fishing effort to that level giving $E^{*}$. Rent dissipation and Pareto-inefficiency with a Nash equilibrium remain since open access remains. Letting $\mathrm{Z}=\Psi$, then $\mu=g(t, \psi, E \psi)$. When regulators manage the fishery by inducing technical inefficiency, it is expected that $\partial \mu / \partial \psi>0$, that is, an increase in the strength of the policy (e.g. shorter seasons) induces increased technical inefficiency or reduced technical efficiency.

The static rent-maximizing yield conditional upon technology and technical inefficiency, $Y_{*}^{T E, t}$, can be found from: $Y_{*}^{T E, t}=q S_{*}^{T E, t} E_{*}^{T E, t} e^{\lambda t-\mu(t, Z)}$. Substituting in the values for $E_{*}^{T E, t}$ and $S_{*}^{T E, t}$ found above gives $Y_{*}^{T E, t}$ :

$$
Y_{*}^{T E, t}=\frac{r K}{4}\left(1-\left(\frac{c}{p q K e^{\lambda t-\mu(t, z)}}\right)^{2}\right)
$$


Whether the rent-maximizing level of yield is higher than the optimal yield in the standard model depends as before on the relative strengths of technical progress and technical inefficiency, but with technical progress and increases in technical efficiency $Y_{*}^{T E, t}>Y_{*}$.

The rent-maximizing yield changes over time:

$$
\frac{\partial Y_{*}^{T E, t}}{\partial t}=\left(\lambda-\frac{\partial \mu(t, z)}{\partial t}\right) \frac{r K}{2}\left(\frac{c}{p q K e^{\lambda t-\mu(t, z)}}\right)^{2}
$$

Holding technical inefficiency constant, technical progress always increases rentmaximizing yield, while increases in technical inefficiency given technology always decreases rent-maximizing yield. These results are due to the fact that the level of optimal stock will always be higher than the MSY-stock level.

These results show that if the fishery policy is based on economic efficiency (e.g. ITQs) then technical progress and overall higher technical efficiency provides a positive net-benefit from a social point of view. The adjustments in effort are under ITQs handled by the private actors in the fishery while the setting of the TAC is the responsibility of the regulators. Setting the right TAC requires following equation (31), knowledge about the biological parameters $\mathrm{r}$ and $\mathrm{K}$ and the economic parameters price/cost relationships, catchability, technical progress and technical inefficiency.

\section{The Backward-Bending Supply Curve with Technical Inefficiency and Technical}

\section{Change}

Equilibrium supply represents the yield from the fishery as a function of the prices of catch and effort and biological parameters under conditions of steady-state equilibrium. To find the static equilibrium supply curve allowing for technical 
inefficiency, substitute $S_{\infty}^{T E, t}$ from (15) into the condition for steady-state equilibrium, $Y=F(S)$, to give:

$$
Y^{T E, t}=\frac{r c}{P q e^{\lambda t-\mu(t, z)}}\left[1-\frac{c}{P q K e^{\lambda t-\mu(t, z)}}\right] .
$$

Because $\left.\partial Y^{T E, t} / \partial t=\left[r c / P q e^{\lambda t-\mu(t, Z)} \llbracket 1-2 c / P q K e^{\lambda t-\mu(t, Z)}\right] \lambda-\partial \mu(t, Z) / \partial t\right]=$ $\left[2 \lambda K e^{\lambda t-\mu(t, Z)} E_{M S Y}^{T E, t} / P \mathbb{1}-[4 c / P K] E_{M S Y}^{T E, t}\right]$, technical progress and gains in technical efficiency raise (lower) sustainable supply when $E_{M S Y}^{T E, t}<(>) P K / 4 c$. The vertical intercept of the static sustainable supply curve becomes:

$$
P^{T E, t}=\frac{c}{K q e^{\lambda t-\mu(t, Z)}}
$$

Technical progress and gains in technical efficiency lower this intercept. The slope now depends on the states of technology and technical inefficiency:

$$
\frac{\partial Y^{T E, t}}{\partial P}=\frac{r c}{P^{2} q e^{\lambda t-\mu(t, Z)}}\left\lfloor-1+\frac{2 c}{P K q e^{\lambda t-\mu(t, Z)}}\right\rfloor .
$$

Price at maximum sustainable yield, $P_{M S Y}^{T E, t}$, now also depends on the states of technology and technical inefficiency:

$$
P_{M S Y}^{T E, t}=\frac{2 c}{K q e^{\lambda t-\mu(t, Z)}}
$$

Because $\left.\partial P_{M S Y}^{T E, t} / \partial t=-\mid 2 c / K e^{\lambda t-\mu(t, Z)} \llbracket \lambda-\partial \mu(t, Z) / \partial t\right]$, both technical progress and gains in technical efficiency lower price at MSY. Maximum static sustainable supply is found by substituting (35) into (32) to give: 


$$
Y_{M S Y}^{T E, t}=\frac{r c}{P_{M S Y}^{T E, t} q e^{\lambda t-\mu(t, Z)}}\left[1-\frac{c}{P_{M S Y}^{T E, t} K q e^{\lambda t-\mu(t, Z)}}\right]=\frac{r K}{4} .
$$

As before, MSY is unchanged by technical progress or technical inefficiency, since it is established by the biological conditions.

\section{Dynamic Model}

The presence of technical inefficiency and technical progress substantially changes the standard normative results through an augmented Golden Rule or fundamental equation of renewable resource exploitation. We demonstrate this result by a simple model of present value maximization of net benefits for a sole owner or social planner derived from exploiting the resource, but in which technical progress and technical inefficiency are now allowed. ${ }^{27}$ The cost diminution in our cost-neutral cost frontier and rent-neutral rent frontier exactly measures technical progress because of the linear homogeneity in $\mathrm{E}$, without confounding by economies or diseconomies of scale. This linear homogeneity in E also yields costs linear in the control variable Y. The introduction of changes in technology and technical efficiency, however, creates an optimization model that while linear in $\mathrm{Y}$ with linear bang-bang approach paths to the steady-state equilibrium resource stock when technology and technical efficiency are static, creates approach paths to the infinite time horizon stock that are now nonlinear.

If $\delta>0$ is a constant denoting the continuous social rate of discount, the objective

may be expressed as: $P V(\pi)=\int_{0}^{\infty} \pi\left[Y_{t}, S_{t}\right] e^{-\delta t} d t$ subject to $d S / d t=F\left(S_{t}\right)-Y_{t}$ and $S_{0}=S(0)$, where $\pi\left[P, c, q, S_{t}, Y_{t}, e^{\lambda t-\mu(t, Z)}\right]=P Y_{t}-c \frac{Y_{t}}{q S_{t} e^{\lambda t-\mu(t, Z)}}=\left[P-\frac{c}{q S_{t} e^{(\lambda t-\mu(t, Z))}}\right] Y_{t}$ from Equation 
(11). The inclusion of time leads to a non-autonomous model.

The present value Hamiltonian allowing for technical inefficiency and technical progress is given by:

$$
H=e^{-\delta t} \pi\left[Y_{t}, S_{t}\right]+\alpha(t)\left(F\left(S_{t}\right)-Y_{t}\right)=e^{-\delta t}\left(P-\frac{c}{q S e^{(\lambda t-\mu(t, z))}}\right) Y_{t}+\alpha(t)\left(F\left(S_{t}\right)-Y_{t}\right),
$$

where $\alpha(\mathrm{t})$ is the present value multiplier. The first-order conditions for a maximum are:

$$
\frac{\partial H}{\partial Y_{t}}=e^{-\partial t} \frac{\partial \pi}{\partial Y_{t}}-\alpha(t)=e^{-\partial t}\left(P-\frac{c}{q S_{t} e^{\lambda t-\mu(t, z)}}\right)-\alpha(t)=0
$$

$$
\frac{\partial H}{\partial S_{t}}=e^{-\partial t} \frac{\partial \pi}{\partial S_{t}}+\alpha(t) \frac{\partial F}{\partial S_{t}}=e^{-\partial t} \frac{c}{q S_{t}^{2} e^{\lambda t-\mu(t, z)}} Y+\alpha(t) \frac{\partial F}{\partial S_{t}}=-\dot{\alpha(t)}
$$

Taking the time derivative of Equation (38) gives:

$$
-\delta e^{-\partial t}\left(P-\frac{c}{q S_{t} e^{\lambda t-\mu(t, z)}}\right)+e^{-\partial t}\left(\frac{c}{q S_{t}^{2} e^{\lambda t-\mu(t, z)}}\right) \dot{S}_{t}+\left(\left(\lambda-\frac{\partial \mu(t, z)}{\partial t}\right) \frac{c}{q S_{t} e^{\lambda t-\mu(t, z)}}\right)=\dot{\alpha(t)}
$$

Equating the right-hand sides of Equations (39) and (40) and simplifying gives an augmented Golden Rule, or fundamental equation of renewable resources, incorporating technical change and technical inefficiency:

$$
\frac{\partial F}{\partial S_{t}}+\frac{c F(S)}{S\left(P q S e^{\lambda t-\mu(t, z)}-c\right)}+\frac{c(\lambda-\partial \mu(t, z) / \partial t)}{\left(P q S e^{\lambda t-\mu(t, z)}-c\right)}=\delta
$$

Compared to the traditional rule, there is a new term added beyond the marginal productivity of the resource $\left(\partial F / \partial S_{t}=r(1-2 S / K)\right)$, and the marginal stock effect $[c F(S)] /\left[S\left(P q S e^{\lambda t-\mu(t, z)}-c\right)\right]$, namely the last term on the left-hand side, the marginal 
technology effect. The marginal technology effect captures the effect of technical progress and increases in technical efficiency on cost. Furthermore, the marginal stock effect is itself augmented by technical change and technical inefficiency.

The singular solution $S_{t}^{*}$ of (41) is (for the logistic growth function):

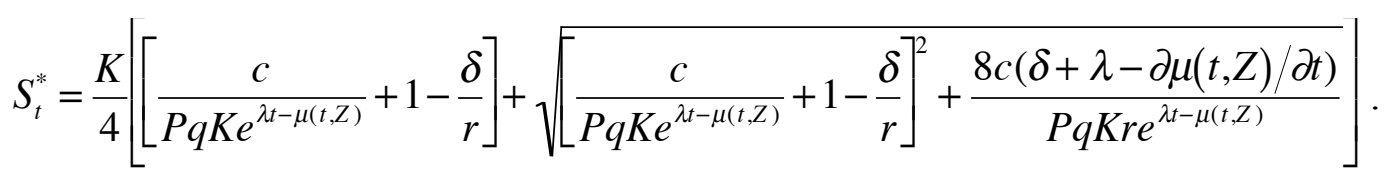

Equation (42) clearly indicates that there is no steady-state solution to the problem. With on-going technical change, the optimal level of the stock declines over time, because $P q K e^{\lambda t-\mu(t, z)}$ increases due to technical progress. However, the short-run effects of introducing technical progress are an increase in the stock size. The new marginal technology effect term is positive with technical progress, so that - all things equal - the stock level is higher compared to the situation without technical progress beyond the marginal stock effect. It can also been seen from the last term in (42). In the traditional model $\lambda$ is not included, and therefore the immediate effect of technical progress is a higher stock level compared to the traditional model. It is now profitable to reduce harvest today because of future technical progress.

However, over time technical progress will lead to lower stock levels, because the unit profit of harvest, $p q S e^{\lambda t-\mu(t, z)}-c$, increases due to technical progress, so that the effect of these terms decline over time. ${ }^{28}$ Notably, the marginal stock effect in the modified Golden Rule, Equation (41), declines in importance under continued technical progress. Harvest costs that increase with declining stock size can be more than balanced by harvest cost diminution through technical progress. ${ }^{29}$ Over time, the marginal stock 
and technology effects decline, requiring continuing increases in the own rate of return to the resource stock, $\partial F / \partial S_{t}$, that follow with declining stock size, given constant $\delta$. The own rate of return is increasingly likely to be positive rather than negative as well. Higher social discount rates or rates of technical progress hasten the stock decline.

A comparison of the marginal stock and technology effects shows that $[c F(S)] /\left[S\left(P q S e^{\lambda t-\mu(t, z)}-c\right)\right]>(<)[c(\lambda-\partial \mu(t, z) / \partial t)] /\left(P q S e^{\lambda t-\mu(t, z)}-c\right)$ as $(F(S) / S)>(<)(\lambda-\partial \mu(t, z) / \partial t)$, or in words the marginal stock effect exceeds (falls short of) the marginal technology effect when the relative growth of the resource stock exceeds (falls short of) the rate of change in technology and technical efficiency. With the logistic growth function this is $r(1-S / K)>(<)(\lambda-\partial \mu(t, z) / \partial t)$, so that higher $r$ or $K$ or lower $\mathrm{S}$ balance higher $\lambda$. Notably, as stock levels decline over time in the face of technical progress, the marginal costs rise to increasingly counterbalance a constant rate of technical progress. With variable rates of technical change, including technical regress, this relationship becomes more complex. The marginal stock effect is comparatively more important in the modified Golden Rule for relatively lower rates of technical progress.

The effect of increases in technical efficiency on $S_{t}^{*}$ for a given state of technology, i.e. no further technical progress, eventually ends if the frontier defined by current technology is reached. This is the case after full diffusion of a technology or fishing skill.

The terms involving $P q K e^{\lambda t-\mu(t, z)}$ in (42) approach 0 in the limit as $t$ approaches infinity: 


$$
\lim _{t \rightarrow \infty} S_{t}^{*}=\frac{K}{4}\left[\left[1-\frac{\delta}{r}\right]+\sqrt{\left[1-\frac{\delta}{r}\right]^{2}}\right]
$$

It can be seen that $\lim _{t \rightarrow \infty} S_{t}^{*} \leq S_{M S Y}$, because the sum of the terms in the brackets is less than or equal to 2 , which contrasts with results showing that $S^{*}$, the economic optimum under static technology, generally exceeds $S_{M S Y}$ (Grafton et al. 2007). ${ }^{30}$ Essentially, over an infinite time horizon technical progress erodes costs to zero and the optimum stock is determined solely by the social discount rate and biological parameters. In the static case, where $\delta=0, \lim _{t \rightarrow \infty} S_{t}^{*}=K / 2=S_{M S Y}$ under continuous technical progress over a long time frame (because costs eventually approach 0); this gives an optimal harvest rate of MSY, which is the standard biological case without costs and prices. When $\delta \geq r, \lim _{t \rightarrow \infty} S_{t}^{*}=0$ or extinction is optimal under continuous technical progress, where technical progress should hasten extinction compared to the case without it. In the intermediate and realistic case, $0<\delta<r$, and $0<\lim _{t \rightarrow \infty} S_{t}^{*}<S_{M S Y}$, which contrast with the traditional dynamic model without technical progress, in which $S_{t}^{*}>S_{M S Y}$ for most reasonable levels of costs and in which stock-dependent costs play a more important role. The optimal stock size given by (43) is exactly the same as the stock size in which the growth rate in the stock is equal to the discount rate, i.e. $F^{\prime}(S)=\delta$, from equation (41). ${ }^{31}$

Differentiating the singular solution $S_{t}^{*}$, Equation (42), with respect to time gives:

$$
\frac{\partial S_{t}^{*}}{\partial t}=-[\lambda-\partial \mu(t, Z) / \partial t] A(t) \frac{K}{4} C(t)
$$


where $A(t)=c / P q K e^{\lambda t-\mu(t, Z)}, C(t)=\left\lfloor 1+\frac{1}{2} B(t)^{-\frac{1}{2}}\left[2\left[A(t)+1-\frac{\delta}{r}\right]+8[\delta+\lambda-\partial \mu(t, Z) / \partial t]\right]\right.$,

and $B(t)$ is the terms inside of the square root in Equation (42). When technical inefficiency is constant, then $\partial S_{t}^{*} / \partial t<0$, i.e. the resource stock declines with technical progress. However, the rate of decline slows, i.e. $\partial^{2} S_{t}^{*} / \partial t^{2}>0$, as shown by:

$$
\frac{\partial^{2} S_{t}^{*}}{\partial t^{2}}=\lambda A(t) \frac{K}{4}\left[\lambda C(t)-\frac{\partial C(t)}{\partial t}\right]
$$

where $\frac{\partial A(t)}{\partial t}=-\lambda A(t)$ and $\frac{\partial C(t)}{\partial t}=-\frac{1}{4} B(t)^{-\frac{3}{2}}\left[2\left(A(t)+1-\frac{\delta}{r}\right)+8(\delta+r)\right]-\lambda A(t) B(t)^{-\frac{1}{2}}$.

The declining stock levels out for a given rate of continuous technical progress and technical inefficiency over an infinite time horizon. Hence with continuous technical progress the optimal stock declines at a slower rate towards a stock level for which the growth rate in the stock is equal to the discount rate, i.e. $F^{\prime}(S)=\delta$.

The singular solution for yield $Y_{t}^{*}$ can be found from the growth equation as $Y_{t}^{*}=F\left(S_{t}^{*}\right)-\frac{\partial S_{t}^{*}}{\partial t}$. Differentiating yield with respect to time gives:

$$
\frac{\partial Y_{t}^{*}}{\partial t}=r \frac{\partial S^{*}}{\partial t}\left(1-\frac{S_{t}^{*}}{S_{M S Y}}\right)-\frac{\partial^{2} S_{t}^{*}}{\partial t^{2}}=-\lambda A(t) \frac{K}{4} C(t)\left[r\left(1-\frac{S_{t}^{*}}{S_{M S Y}}\right)+\lambda\right] .
$$

The sign of $\partial Y_{t}^{*} / \partial t$ can be either negative or positive depending on the optimal stock size. For a given stock level greater than $S_{M S Y}$, the sign of $\partial Y_{t}^{*} / \partial t$ is positive. For stock levels lower than the given stock level, the sign is negative, and the optimal yield will from a given point in time will decline. In more detail, if $S_{t}^{*}<S_{M S Y}$ the sign of the sum of 
the terms in the brackets is positive and together with the negative sign of the term outside the brackets it results in $\partial Y_{t}^{*} / \partial t<0$. If $S_{t}^{*}>S_{M S Y}$, the sign of the sum of the terms depends on the relative size between $S_{t}^{*} / S_{M S Y}$ and the rate of technical progress. The sign of $\partial Y_{t}^{*} / \partial t$ is positive for sufficiently high stock levels. For a given stock level higher than MSY, $\partial Y_{t}^{*} / \partial t$ is zero. In contrast to the traditional dynamic model, $Y_{t}^{*}$ is now conditional upon the state of technical progress and technical inefficiency as well as the entire set of bioeconomic parameters.

[Figure 4 about here]

Figure 4 illustrates examples of paths for the optimal yield. The path beginning in $\mathrm{Y}_{1}$ - a high yield level - is declining over time and hence the optimal stock level at the initial time is less than the stock level, where $\partial Y_{t}^{*} / \partial t$ is zero. The path beginning in $\mathrm{Y}_{2}$ is first increasing indicating that the initial optimal stock level is above the stock level, where $\partial Y_{t}^{*} / \partial t$ is zero. Since the optimal stock level decreases, the yield will inevitably begin to fall. Finally, the path beginning in $\mathrm{Y}_{3}$ has an even higher initial optimal stock level, so that the period with increasing yield is longer. To sum up, the optimal yield path is more complicated than the constant equilibrium path obtained in the traditional dynamic model. $^{32}$ The time period with the complicated course is followed by a period where the yield path asymptotically approaches the level, where $F^{\prime}\left(S^{\infty}\right)=\delta$, given by $Y^{\infty}=\frac{r K}{2}\left(1-\frac{\delta}{r}\right)\left(1+\frac{\delta}{r}\right) \cdot^{33}$

The singular solution for $E_{t}^{*}$ is found from the production frontier as:

$$
E_{t}^{*}=\frac{Y_{t}^{*}}{q S_{t}^{*} e^{\lambda t-\mu(t, Z)}}=\frac{r S_{t}^{*}\left(1-\frac{S_{t}^{*}}{K}\right)+\lambda A(t) \frac{K}{4} C(t)}{q S_{t}^{*} e^{\lambda t-\mu(t, Z)}} .
$$


The sign of the time derivative of effort, $\partial E_{t}^{*} / \partial t$, can be shown to be negative (positive) below (above) a certain level of the stock which is higher than $S_{M S Y}$. Hence, given high initial optimal stock levels, in the short and medium run the optimal effort level increases, but over time with technical progress the optimal level of effort starts to decline, because the optimal stock level declines. Similarly, for stock levels below the stock level, where $\partial E_{t}^{*} / \partial t=0$, gains in technical efficiency for a given state of technology lower $E_{t}^{*}$ until the frontier is reached.

\subsection{Biased Technical Change}

Technical change can be biased towards using more or less effort or the resource stock, in which the direction of bias can be induced by the state of property rights (Smith 1972, Ruttan 2001). Resource-using technical change in a stock-flow production process can be viewed as allowing more effective use of the entire, existing resource stock (not increasing the overall stock size or giving more catch biomass from the existing stock biomass), such as allowing exploitation of formerly unreachable and unfished fishing grounds, harvesting of previously undersized fish, or detection of formerly unknown stocks (much like increasing the economic reserves of an exhaustible resource). Specifying autonomous technical change as input-augmenting by the use of efficiency units for both effort and the resource stock with the Schaefer (or Cobb Douglas) production function does not allow identifying the individual efficiency gains for effort and stock. Thus, $Y_{t}=q\left(e^{\lambda_{1} t} E_{t}\right)^{\alpha}\left(e^{\lambda_{2} t} S_{t}\right)^{\beta}=q e^{\alpha \lambda_{1} t} e^{\beta \lambda_{2} t} E_{t}^{\alpha} S_{t}^{\beta}=q e^{\left(\alpha \lambda_{1}+\beta \lambda_{2}\right) t} E_{t}^{\alpha} S_{t}^{\beta}$, where $\alpha=\beta=1$ for the Schaefer model. An alternative allowing identification of technical change is a modified Cobb-Douglas functional form: 


$$
Y_{t}=q E_{t}^{\beta_{1}+\lambda_{3} t} S_{t}^{\beta_{2}+\lambda_{4} t} e^{\lambda_{1} t+\lambda_{2} t^{2}}
$$

where $\beta_{1}=\beta_{2}=1$ with the Schaefer model. In log-linear form,

$\ln Y_{t}=\ln q+\beta_{1} \ln E_{t}+\beta_{2} \ln S_{t}+\lambda_{1} t+\lambda_{2} t^{2}+\lambda_{3} \ln E_{t} t+\lambda_{4} \ln S_{t} t$ and

$\partial \ln Y_{t} / \partial t=\lambda_{1}+\lambda_{2} t+\lambda_{3} \ln E_{t}+\lambda_{4} \ln S_{t}$, where $\lambda_{3}>(<) 0$ indicates technological change

that is effort using (saving) and $\lambda_{4}>(<) 0$ indicates resource using (saving).

\section{Renewable Resource Policy}

Consider next the use of taxes to induce the social optimum when there is technical progress and initially open access. Under open access, fisher behavior leads to the open-access equilibrium with dissipated rents (Gordon 1954). From the rent frontier

in Equation (11) under open access, price is equal to unit cost, i.e. $\left.P=c / \lg e^{\lambda t-\mu(t, Z)} S_{t}\right\rfloor$. From the first-order conditions for the Pareto optimum with the dynamic model given in Equation (38),

$$
P-\frac{c}{q S_{t} e^{\lambda t-\mu(t, z)}}=e^{\delta t} \alpha(t)=\beta(t),
$$

where $\beta(t)$ is the current value costate variable or the marginal user cost, which now varies over time with the state of technology and technical efficiency. To align the private incentives with the optimal solution a tax equal to $\beta(t)$ can be implemented. Because the proportional rate of change in optimal stock with respect to time is numerically less than the rate of technical progress, the unit cost decreases over time. ${ }^{34}$ Hence, with constant biological and economical parameters the tax rate will increases over time. However, from a practical viewpoint, the regulator has to recalculate the tax rate every year, 
because, without steady-state equilibrium, the optimal level of stock and yield is changing due to technical progress. Rates of technical change that vary by time period or even regress further complicate the setting of taxes. Further, in the traditional dynamic model the tax rate has to be adjusted every year as economic and biologic parameters change, making the use of tax policy difficult in practice. The analysis shows that adding technical progress and technical inefficiency into the bioeconomic model makes it even more complicated to set the optimal tax rate.

The shadow price of natural capital or the common renewable resource stock, Equation (38), reflects direct use value, representing the marginal user cost along the optimal trajectory of the resource in the face of technical progress and changes in technical efficiency. This equation does not include the indirect use values from the public goods of the broader ecosystem and its services in which the resource stock is embedded and makes a contribution as a predator or prey or the indirect use and existence value of the stock's biodiversity. When only capturing direct use value, the shadow price can be expected to grow over time under technical progress, but as stock levels reach lower levels and the opportunity cost of its increasingly foregone public good contributions rises, the net value of the stock will decline, although this value is not captured by the fundamental equation of renewable resources or its modification in Equation (41).

Under ITQ regulation, the regulator has to adjust the total quota so that the equilibrium price in the quota market equals the shadow value of the stock. In principle, this requires exactly the same information as the tax policy. ${ }^{35}$ However, the division of work has been that the biologist sets a total quota based on biological criteria and the 
fishermen adjusts their fishing costs by quota trading, leading to a cost-efficient fleet. The setting of total quotas is not based on the outcome of a dynamic fishery model. Under ITQ regulation, the TAC has to be recalculated on an on-going basis to account for technical progress (Murray 2007). Critically, the optimum fleet size and fishing capacity must adapt to the TAC of an optimum resource stock that declines over a range before reaching a limit as in Equation (43), and which is below that of a steady-state equilibrium not accounting for changes in technical inefficiency and technology, given by the augmented Golden Rule with the technology term. Empirical experience bears this out in the Southeast Trawl fishery of Australia, where a fisheries buyback was required to remove excess capacity even after an ITQ program was introduced (Fox et al. 2007). The point is that excess capacity can be expected to persist for even long periods of time after an ITQ is introduced and other measures may be required to reduce excess capacity (Vestergaard et.al. 2005). To sum up, under ITQs a well-functioning quota market is needed to achieve a cost-efficient fleet. This point is reinforced by introducing technical progress. Further, the setting of the total quota is more complicated with technical progress, but in practice this might not influence the quota policy, because in many cases the quota is determined only by biological considerations (Squires et.al. 1995).

\section{Empirical Example: The U.S.-Canada Albacore Fleet}

The empirical example applies the concepts of output-oriented technical efficiency and technical change to the single-species U.S. and Canadian troll fleets fishing for North Pacific albacore (Thunnus alalunga) over 1981-2006 to examine the optimal stock, yield, and tax time paths. The case study examines both constant and timevarying rates of technical progress to demonstrate the additional complexity introduced 
into the modified Golden Rule and optimal exploitation when more realistic specifications of technical change are allowed. The data used are for the U.S. and Canadian troll fleets, but the bioeconomic results obtained in the simulation should closely match the bioeconomics for the entire North Pacific albacore fishery of troll, pole-and-line, and other surface gear for Taiwan, Japan, Korea, U.S., and Mexico, since catch per unit effort indices for these other surface fisheries closely track those of the U.S. and Canadian troll fishery. The industry was not regulated over the period of study, implying no regulatory-induced technical change.

The U.S. and Canadian albacore troll fleets are comprised of family-owned vessels harvesting northern albacore from about $150^{\circ} \mathrm{E}$ eastward. The albacore, aged about 2-5 years (but predominately ages 3 and 4), are sexually immature, school and swim near the ocean surface, and are caught by troll lines employing jigs. During AprilMay, distant-water troll vessels begin fishing albacore in the central Pacific Ocean (around the International Date Line). As the fish become available off the North American coast in June and early July, the distant-water fleet moves closer to the coast and coastal vessels enter the fishery. The U.S. and Canadian vessels have access to each other's waters and ports through an international treaty, with Canadian vessels harvesting in U.S. waters on a frequent basis due to a preponderance of fish there. The fishery utilizes relatively small vessels, with the U.S. vessels averaging 43 feet in length. The average year of construction of 1976 suggests a fleet with vessels that are relatively old and stable. The average U.S. skipper has 28.9 years of fishing experience, 21.1 years of albacore troll experience, and has been with the vessel an average of almost 14 years (Squires et al. 2003). The fishery is largely well established and "mom-and-pop", with 
innovation adoption only incompletely diffused and varying by innovation. The electronic process innovations used by the U.S. fleet in 1999 include (percent adopters in parenthesis): depth sounders (43\%), radar sensor (71\%), temperature gauges (54\%), telex (17\%), fax (29\%), cell phone (51\%), satellite phone (6\%), video plotters (9\%), direction finders $(6 \%)$, GPS (71\%), sideband radio (75\%), ham radios (31\%), VHF (57\%), comsat satellite navigation ( $0 \%)$, Doppler radar $(0 \%)$, autopilot (78\%), PC or laptop (57\%), sonar $(20 \%)$, color sounder $(6 \%)$, and IMARSAT $(23 \%)$. The mean value $(\$ 2001)$ of these innovations per vessel over 1996-1999 was \$287, compared to a mean insured replacement value of the vessel of $\$ 365,758$.

The empirical analysis employs the catch and days fished data used in the international stock assessments by the population biologists of the fishery's representative countries (McDaniel, Crone, and Dorval 2006). These catch and days fished data are for all landings by all vessels. Appendix I discusses these and the economic data. The intrinsic growth rate, $r=0.18$, and the environmental carrying capacity, $\mathrm{K}=250$ metric tons, were provided by an albacore population biologist and were developed from life history studies, population assessments, and other biological research, and can be treated as exogenous. The catchability coefficient, $q$, is 0.00526169 , comes from international stock assessments, and is the weighted average of age-specific values of $q$ for 2,3,4, and 5-year old year classes (one-third weights for 3 and 4 year olds and one-sixth weights for 2 and 5 year-olds). The estimates of biomass (resource stock) also come from international stock assessments. The albacore landed are largely for the canned and blast bled frozen tuna markets and are only small part of the global albacore market, which in turn is part of a highly competitive global market for canned tuna from 
other species, so that the ex-vessel price can safely be viewed as exogenous with respect to own landings. Similarly, prices of inputs used by albacore troll vessels can be expected constant, since the quantities used are insufficient to affect prices. The ex-vessel albacore price and cost per vessel per day (US\$2001) were set at the 1981-2006 means, giving $P=\$ 2,852.24 / m t$ and $c=\$ 1,268.48 /$ vessel-day, where $c$ includes the operating costs of fuel, oil, food, gear, and labor, and capital costs of loan payments and insurance. The discount rate is $2.5 \%$.

To obtain values of the rate of technical change $\lambda$ and the change in technical efficiency $\partial \mu(t, Z) / \partial t$, the following Cobb-Douglas production function was estimated using the unbalanced panel data for the U.S. and Canadian fleets' catch and effort:

$$
\ln Y_{i t}=\alpha+\beta_{1} \ln E_{i t}+\beta_{2} \ln S_{i t}+\lambda t+a_{i}+a_{i} E_{i t}+v_{i t},
$$

where $i$ indexes the individual country, $a_{i}$ captures the fixed effect (and is allowed to be correlated with $E_{i t}, S_{i t}$ in an unknown correlation structure), in this case Canadian effort, and $v_{i t}$ is an $i . d . d$. stochastic disturbance term with a zero mean, finite variance, and normal distribution. Technical inefficiency $\widehat{u}_{i t}$ is measured semi-parametrically by (Schmidt and Sickles 1984): $\widehat{u}_{i t}=\max _{j}\left(\widehat{a}_{j}+\widehat{a}_{j} E_{j t}\right)-\left(\widehat{a}_{i}+\widehat{a}_{i} E_{i t}\right)$, which reduces to the relative technical inefficiency between two countries. This approach specifies a timevarying, non-neutral form of technical inefficiency, a semi-parametric version of Huang and Liu (1994). This measure varies over time, because effort varies over time, and is non-neutral because the measure varies with effort. Differences between U.S. and Canadian vessels reflect differences in biophysical conditions, notably the preponderance of albacore in U.S. rather than Canadian waters, requiring Canadian vessels to travel longer distances to reach fishing grounds. The limited number of countries in our data set 
precludes an explicit time-varying semi-parametric specification of technical inefficiency -- parameterized as a function of time and even parameters that vary over firms -- and still identifying technical progress. ${ }^{36}$ The limited number of observations also precludes evaluating biased technical change.

We also estimated a time-varying general index of Hick's neutral technical change as an alternative to the time trend "straightjacket" and to more closely examine technical progress and optimum stock size over the range of the data set (Baltagi and Griffin 1988). This general index of technical change specifies a dummy variable for each year, requires panel data, and is essentially a Solow residual. The production function with the general index of Hick's neutral technical change and country-specific dummy variable for Canada to allow for semi-parametric estimation of technical inefficiency is specified: ${ }^{37}$

$$
\ln Y_{i t}=\beta_{1} \ln E_{i t}+\beta_{2} \ln S_{i t}+A(t)+a_{i}+v_{i t},
$$

where $A(t)$ denotes the general index of technical change that varies by year. Because $A(t)$ is unobserved, annual dummy variables $D_{t}(t=1, \ldots, T)$ are used to give:

$$
\ln Y_{i t}=\beta_{1} \ln E_{i t}+\beta_{2} \ln S_{i t}+\beta_{3} D_{t}+a_{i}+v_{i t} .
$$

The base years consist of 1981-1982 rather than a single year to overcome singularity and to obtain plausible estimates with the limited panel and degrees of freedom. The restriction $\beta_{3}=\alpha+A(t)$ is imposed in Equation (52) for estimation. The rate of technical change, given by $A(t)-A(t-1)$, allows for Hick's-neutral technical change that is not constant, comparable to $\lambda t+\phi t^{2}$ in Equation (50). Taking 1981-1982 as the base period for $A(t)$, so that $A(1)=0$ allows identification of $a_{i}$ and the index $A(t)$. The general index of technical change is calculated following Equation (7) of Baltagi, Griffin, and 
$\operatorname{Rich}(1995)$ as $\exp [A(t)] .{ }^{38}$

We specify a measure of the composite input, effort, comprised of both days fished and the number of vessels as the first stage in a two-stage decision-making process. This approach provides an instrumental variable predetermined in the effort model that avoids endogeneity issues and reduces multicollinearity when estimating the second-stage (Fuss 1977). ${ }^{39}$ Technical progress is not specified in the effort aggregator function, but under the linear homogeneity of this function in E, factor-augmenting technical change that equally augments each input comprising $E_{t}$ is equivalent to outputaugmenting technical change (Thirtle and Ruttan 1987).

Two approaches to the linearly homogeneous aggregator function of the composite input effort were adopted. The composite input effort was first constructed as a Tornqvist chain index of days fished and vessel numbers because the corresponding translog functional form for this superlative aggregator function (Diewert 1976) corresponds to the separability inflexibility of input-output separability and the CobbDouglas functional form of the catch production frontier (Denny and Fuss 1977). ${ }^{41}$ Annual variable input costs shares correspond to the costs of fuel, labor, food, and gear and the annual capital cost shares correspond to the capital services prices of the vessels (Appendix I).

The index of unobserved effort was also created, following Fuss (1977) and Squires (1987), as a generated regressor (Murphy and Topel 1985), and retrieves the actual values of the aggregator function. Consistent with the separability inflexibility of the Cobb Douglas catch equation with input-output separability, a linearly homogeneous translog effort aggregator function was specified, which gives a superlative effort index 
equivalent to the Tornqvist discrete approximation to the Divisia. Fitted values from the estimated effort aggregator function, Equation (53) below, provide an estimate of effort (up to the arbitrary scaling factor $\alpha+a_{i}$ in Equation (53)) and predetermined variable for unobserved (log of) endogenous effort in the catch frontiers, Equations (50) and (52), and allow effort to be exogenous in the second stage of decision-making. ${ }^{42}$ The translog effort aggregator function (with time-invariant technical inefficiency) is:

$$
\ln E_{i t}=\alpha+\alpha_{1} \ln X_{1 i t}+\alpha_{2} \ln X_{2 i t}+\alpha_{12} \ln X_{1 i t} \ln X_{2 i t}+a_{i}+a_{i 1} X_{1 i t}+a_{i 2} X_{2 i t}+\varepsilon_{i t},
$$

where $X_{1 i t}$ denotes days fished for country $i$ in time $t$, a measure of variable input usage, $X_{2 i t}$ denotes the number of vessels for country $i$ in time $t$, a measure of the capital stock, and symmetry is imposed by $\alpha_{12}=\alpha_{21}{ }^{43}$ Assuming competitive markets, differentiating Equation (53) with respect to $\ln X_{1 i t}$ and $\ln X_{2 i t}$ yields the cost share equations:

$$
\begin{aligned}
& \partial \ln E_{i t} / \partial \ln X_{1 i t}=M_{1}=\alpha_{1}+a_{i 1}+\alpha_{11} \ln X_{1 i t}+\alpha_{12} \ln X_{2 i t} \\
& \partial \ln E_{i t} / \partial \ln X_{2 i t}=M_{2}=\alpha_{2}+a_{i 1}+\alpha_{12} \ln X_{1 i t}+\alpha_{22} \ln X_{2 i t},
\end{aligned}
$$

where $M_{1}, M_{2}$ are the cost shares for days and vessel numbers. Linear homogeneity is imposed by $\alpha_{1}+\alpha_{2}=1, a_{1}+a_{2}=0, \alpha_{11}+\alpha_{12}+\alpha_{22}=0$. Since the cost share equations sum to unity, the vessel numbers equation is dropped, only the variable input equation is estimated by ordinary least squares, and the results are invariant to the choice of dropped equation. The variable input cost share equation and the production frontier were simultaneously estimated by maximum likelihood.

The generated regressor approach is preferred to the index number approach, but the additional parameterization of the general index approach to technical change precludes its use in this instance because of limited observations. Hence, we apply index numbers to the general index approach and the generated regressor approach to the time 
trend specification of technical change.

The time frame of analysis was 1981-2006 for U.S. vessels and 1995-2006 for Canadian vessels to match the availability of data. The data are unbalanced panel.

We also estimate a two-factor learning curve that accounts for the stock-flow nature of the production technology (since rates of cumulative catch could slow down not from declining learning but from lower resource stocks making less catch available for accumulation):

$$
\ln Y_{i t}=\alpha+\beta_{1} \ln y_{i}+\beta_{2} S_{t}+a_{i}+\varepsilon_{i t},
$$

where $y_{i}$ denotes cumulated production in time t.

\section{Empirical Results}

The catch frontier with constant Hick's neutral technical change Equation (50) using the Tornqvist index of effort was estimated by maximum likelihood with the effort coefficient restricted to one (consistent with the Schaefer specification). Evidence of firstorder serial correlation led to maximum likelihood estimation correcting for first-order serial correlation. ${ }^{44} \mathrm{~A}$ t-test for the null hypothesis that the effort coefficient equals one gave a t-value of -6.73 , rejecting the null hypothesis; nonetheless, we maintain the specification consistent with the classic Gordon-Schaefer model. Parameter estimates of Equation (50) are reported in Table 4, $R^{2}=0.828$, Canadian vessels are less technically efficient, and there is a statistically significant rate of technical change of 4.27 percent (tratio of 2.03). ${ }^{45}$ This result led to a final specification of constant Hick's neutral technical change in the modified Golden Rule. Given the constant returns to scale for effort (coefficient of one) and allowance for technical inefficiency, technical progress is equivalent to total factor productivity growth. 
The general index of technical change model, Equation (52), using the Tornqvist index of unobserved effort and the Schaefer restriction that the effort coefficient equals one, was estimated by ordinary least squares with the base period of 1981-1982 rather than simply 1981 due to multicollinearity and with a dummy variable for Canada. Evidence of serial correlation led to maximum likelihood estimates correcting for firstorder serial correlation. ${ }^{46}$ A t-test for the null hypothesis that the effort coefficient equals one gave a t-value of -16.40858 , rejecting the null hypothesis; nonetheless, we again maintain the specification consistent with the classic Gordon-Schaefer model. A likelihood ratio test that the annual dummy variables are jointly zero was rejected at five percent significance $\left(\chi_{d f=24}^{2}=54.39\right.$, critical value of 36.415). The final parameters estimates for Equation (51) are reported in Table 5, $R^{2}=0.948$, and Canadian vessels are statistically less technically efficient than U.S. vessels.

The production frontier with constant Hick's-neutral technical change (50) and the variable input cost share equation for the generated regressor index of unobserved $E_{t}$ (54), were jointly estimated by full information maximum likelihood with a serial correlation correction for (17a). A likelihood ratio test failed to reject the classic GordonSchaefer specification $\beta_{1}=1\left(\chi_{d f=1}^{2}=0.6032\right)$, and conditional upon $\beta_{1}=1$, a likelihood ratio test failed to reject $\beta_{2}=1\left(\chi_{d f=1}^{2}=1.2356\right)$. The parameter estimates are reported in Table 6 for (54) and Table 7 for (50) with $R^{2}=0.92$ for (54) and $R^{2}=0.83$ for (50). The Debreu-Farrell best practice frontier defined by U.S. vessels expands at an annual rate of 3.56 percent due to technical progress. ${ }^{47}$ Canadian vessels' state of technology always lags behind the expanding frontier.

The general index model, Equation (52) using the effort aggregator function (53) 
had an excessive number of parameters for estimation.

The two-factor learning curve, Equation (55), estimated by maximum likelihood with a first-order serial correlation correction gave a statistically significant value for the natural $\log$ of the cumulated production coefficient, indicating an annual rate of technical change of 10.89 percent (Table 8$).{ }^{48}$ Because this value is unrealistically high, we retain our focus on the catch frontier approach. Nonetheless, this result reinforces our finding of important technical change.

Figure 5 illustrates northern albacore stocks over a 150-year time horizon with constant annual Hick's neutral technical progress of 3.56 percent for: the fundamental equation of renewable resources with static technology $S^{*}$; with technical progress (8) $S_{t}^{*} ; S_{M S Y}=K / 2 ;$ the limit stock over an infinite time horizon with technical progress (9); and the open-access equilibrium stock with technical progress (the initial value is the open access stock under static technology) $S_{\infty}^{T E, t}=c /\left[P q e^{\lambda t-\mu(t, Z)}\right]$. The results clearly illustrate the wide divergence between $S^{*}=159.12 m t, S_{t}^{*}, \lim _{t \rightarrow \infty} S_{t}^{*}=107.64 m t$, $S_{M S Y}=125 \mathrm{mt}$, and $S_{\infty}^{T E, t}$, which is $84.52 \mathrm{mt}$ in the initial time period and $0.41 \mathrm{mt}$ in the fina time period. $S_{t}^{*}>S^{*}$ for a finite number of years, as discussed earlier, before $S_{t}^{*}$ drops below $S^{*}$, steadily diverging from $S^{*}$, and eventually reaches the limit stock. The slowing rate of decline with technical progress reflects (11). Notably, the limit stock lies below not only $S^{*}$ but also $S_{M S Y}$ as the marginal technology effect dominates and steadily erodes the marginal stock effect over time. $S^{*}$ lies well above $S_{M S Y}$ due to the marginal stock effect and cost savings from keeping fish in the water, but represents an opportunity cost of foregone rent with technical progress.

The effect of technical progress on $S_{\infty}^{T E, t}$ in Figure 5 is striking, demonstrating the 
importance of property rights or an optimum tax, the dangers of ignoring the rapid stock decline due to technical progress - especially under open access, and the low levels that $S_{\infty}^{T E, t}$ can reach. The current state of high seas fisheries for valuable highly migratory species, such as bluefin tunas (which face extinction), reflect rapid technical change under open access. The difference $S_{t}^{*}-S_{\infty}^{T E, t}$ measures the resource stock externality under technical change, which increasingly diverges over time due to the march of technical progress. However, although steadily diverging, the externality, which begins at $86.2 \mathrm{mt}$, levels off at it asymptotically approaches $107.64 \mathrm{mt}$, as $\lim _{t \rightarrow \infty} S_{t}^{*}=107.64 \mathrm{mt}$ and $\lim _{t \rightarrow 0} S_{\infty}^{T E, t}=0 m t$, i.e. $\lim _{t \rightarrow 0} S_{t}^{*}-\lim _{t \rightarrow 0} S_{t}^{T E, t}=\lim _{t \rightarrow 0} S_{t}^{*}$. Higher rates of technical progress exacerbate the external cost under open access by strengthening the resource stock externality and hastening the decline in stock size and foregone rents.

Figure 6 presents optimum yields over 150 years corresponding to the optimum resource stocks in Figure 2. $Y^{*}$ is $10.41 \mathrm{mt}$ and $Y_{M S Y}=r K / 4$ is $11.25 \mathrm{mt}$. Optimum yields in the early years of technical progress reflect stock rebuilding and matches $Y_{2}$ in Figure 1. $Y_{t}^{*}>Y^{*}$, and the lower costs due to technical progress lead to net benefits to society of higher harvest rates than without technical progress in which the only source of lower costs is retaining a higher resource stock in the water

This relationship between the marginal stock effect and the marginal technology effect over 150 years is illustrated in Figure 7. The marginal technology effect in the albacore fishery always dominates the marginal stock effect, since $\left(F\left(S_{t}\right) / S_{t}\right)<(\lambda-\partial \mu(t, z) / \partial t)$, and the marginal stock effect is minimal and quickly eroded through technical change.

Different species of fish concentrate (school) differently. Fish are evenly 
dispersed throughout the ocean when $\beta_{2}=1$, whereas if the stock schools or contracts as it is depleted and preserves its density $\beta_{2}=0$ (Hannesson 1993). Values of $1,0.5$, and 0.1 were assigned to $\beta_{2}$ to reflect the stock's schooling. The results in Figure 8 indicate an even lower optimal stock size for schooling species, reflecting the accelerated effect of technical progress on harvests due to concentration of fish and their consequent increased ease of location and lower harvest cost. The stock limits for $\beta_{2}=0.1$ compared to $\beta_{2}=1$ illustrate just how low the optimum stock can become, close to extinction and almost indistinguishable from open access, under technical progress and schooling. For some schooling and highly valuable species under open access, such as giant bluefin tunas, the economic optimum differs little from open access when technical change is considered.

The impact of technical change on the optimum tax is illustrated in Figure 9. The optimum tax rises over time to level off. With technical change, the optimum tax must be updated every time period until the externality narrows enough to be de facto negligible.

Figure 10 illustrates the static resource stock externality over 1981-2006, developed in Section 4.2. with the linear time trend model and the Tornqvist index of effort. This externality is the difference between the marginal and average products of effort: $M P_{E}^{T E, t}-A P_{E}^{T E, t}=-\frac{q^{2} K E_{t} e^{2 \lambda t-2 \mu(t, Z)}}{r}<0$. As expected, technical progress exacerbates the external costs over time, although the amount varies according to the level of effort and can even increase when the level of effort declines. Higher rates of technical progress can be expected to increase the external cost by strengthening the resource stock externality, and in principle the social return to technical progress under open access can be negative. 


\section{Concluding Remarks}

Progress in technology and technical efficiency under incomplete property rights exacerbates the commons problem, further widening the wedge between the private and social costs of resource exploitation - the negative resource stock externality. The resource stock declines more rapidly than under static technology, which is hastened under resource-using technical change and the more a species schools or concentrates. Extinction can also be hastened. The rapid technical progress over the past 150 years undoubtedly contributed to the decline of most, if not all, global fisheries.

Changes in technology and technical efficiency can markedly alter the optimum exploitation of common renewable resources. Accounting for these changes alters the fundamental equation of renewable resources or Golden Rule by modifying the existing marginal stock effect and introducing the new marginal technology effect.

Economically optimum harvest costs that increase with declining stock size can be more than balanced by harvest costs declining through progress in technology and technical efficiency. The optimal resource stock declines over time to reach, over an infinite time horizon, a level that can be notably less than the steady-state economic optimum under static technology and even less than the stock of maximum sustainable yield, $S_{M S Y}$. This result can markedly differ from conventional wisdom (Grafton et al. 2007), in which the dynamic economic optimum stock under static technology exceeds $S_{M S Y}$, in large part due to the marginal stock effect. The realistic possibility of an economic optimum stock below $S_{M S Y}$ also suggests that at least some of the approximate $75 \%$ of global fish stocks that lie at or below MSY (FAO 2006) may not be economically overexploited after all, and that from an economic perspective the current crisis in global 
fisheries may be overstated. The present near-universal policy in global fisheries of managing for MSY (sometimes modified by a precautionary level) may in some instances be economically sub-optimal by surprisingly favoring stocks too large rather than too small, and can create an opportunity cost of forgone rents. Managing renewable resources for a non-existent steady-state economic optimum under static technology sets inappropriate targets for yields, effort and resource stocks and exacerbates the opportunity cost of foregone rents.

In sum, accounting for changes in technology and technical efficiency creates the potential for turning conventional normative economic fisheries management on its head by allowing for the very real possibility of dynamic economic optimum stock sizes below $S_{M S Y}$, lowering or even removing the importance of retaining fish in the water to reduce harvest costs and increase asset value, and shifting the management focus away from input to output controls. Nonetheless, sound ecological and biodiversity reasons may well argue for larger resource stocks, richer biodiversity, and larger-sized fish (Worm et al. 2006, Anderson et al. 2008), reinforced by uncertainty, non-convex and nonlinear ecosystems, and non-market amenity values. Common resources increasingly require management as public goods rather than simply as the historic "commons problem" and direct use value. The economic benefits from technological progress can best be fully realized under well-developed individual or group property rights on outputs (Costello et al. 2008, Heal and Schlenker 2008), but perhaps at lower, sometimes perhaps even much lower, resource stock levels than previously believed. 


\section{Appendix I: The Data}

The catch and effort data are those used for the international resource stock assessments of North Pacific albacore (McDaniel, Crone, and Dorval 2006). Effort is measured by the number of days fishing. Albacore price data, which correspond to each fishing trip's sales from the vessel to fish processors (ex-vessel data), are from all landings of albacore troll vessels over 1981-2006 along the Pacific coast of the United States.

Cost data were centered upon a panel of cost data over 1996-1999 for individual troll vessels, which the albacore industry collected (Squires et al. 2003) and is discussed further below. These benchmark costs reflect the state of technology and technical inefficiency over this time period. With the exception of three vessels, the panel data set was balanced. To extend the cost data backward to 1981 and forward to 2006, variable and fixed input costs per day were assumed to change at the same annual rate as their associated input prices. U.S. Bureau of Labor Statistics economic producer or consumer price indices (not seasonally adjusted) were used for labor (compensation: wages and salaries for construction, extraction, farming, fishing, and forestry occupations), food (Portland-Salem, Oregon-Washington), and gear (machinery and equipment) for periods before 1996 and after 1999. The capital service price used that year's mean daily interest rate for seasoned bonds rated Baa by Moody's. Annual fuel price changes were calculated from an average of monthly dockside number two marine diesel fuel prices for 600 gallons cash price before tax by port for Washington (13 ports), Oregon ( 7 ports), and California (11 ports) over 1981-1988 and 2000-2007. Because actual fuel prices were unavailable over 1988-1995, the producer price index for fuels and related products and power was used to fill in the gaps. The opportunity cost of labor, discussed in detail below, was available for 1981-1985 and 1996-2007 with the gap years filled in by the use of the BLS index for construction average hourly earnings, where blue collar work is the expected alternative to serving on a vessel. Because effort (and the resource stock) is assumed in equilibrium, the capital stock is specified to be in equilibrium in each period, leading to the use of a capital services price rather than a quasi-rent to allow for variations in capacity utilization. This specification is consistent with the cost per unit effort, c, variable in each time period and the implicit assumption of instantaneous entry and exit. Capital services prices were constructed using the above interest rate and a depreciation rate of seven percent and insured replacement value from the panel data set over 1996-1999 All economic data were deflated by the GDP implicit price deflator to provide values in $\$ 2001$.

All variable input cost changes were weighted by the mean 1996-1999 cost shares of labor, food, diesel fuel and oil, and gear to provide an index of annual changes for variable cost per day, and similarly for the vessel (includes engine, equipment, etc.) for the rate of change of Moody's long-term bond rate rated Baa. The annual rates of variable and fixed cost changes per day were used to extend the 1996 observed mean variable and fixed cost per day from the panel data set backwards from 1996 and forwards from 1999 to provide a variable and fixed cost per day of fishing, which when multiplied by each year's total days fished gave the fleet's annual total cost. The use of these cost-shares 
implies that the single-product harvest technology was Leontief or fixed over this time period for variable and fixed costs, which also satisfies Leontief aggregation theorem for a composite input, effort. This Leontief separability is consistent with the homothetic input separability of all inputs required to construct the composite input fishing effort. The cost shares are independent of the technology index $t$ under implicit Hick's input neutrality.

The panel cost data are from a survey of vessel annual cost-and-earnings for the Washington-Oregon-California albacore troll fleet covering the years 1996-1999 conducted by the American Fishermen's Research Foundation, the Western Fish Boat Owners' Association, and the National Marine Fisheries Service (NMFS), in conjunction with the Pacific States Marine Commission (Squires et al. 2003). The survey was based on a stratified random sample determined by the Neyman Allocation Method with a finite population correction for $95 \%$ level of precision (significance) for a 10\% error term from the mean 1996-97 albacore troll landings (these population data are all landings of fish along the Pacific Coast at the point of first sale) for a single year of data, although four years of panel data were collected. All strata received small rounding toward the closest integer. The sample size was 88 , but to allow at least 3 vessels in each sample (to satisfy NMFS confidentiality requirements), several strata received additional vessels to give a final sample size of 92 . The level of precision and error should actually exceed $95 \%$ and $10 \%$ for a full sample since four years rather than one year of data were obtained. There were 14 strata, which were developed in consultation with the Western Fish Boat Owner's Association. The data were collected double blind to NMFS to insure confidentiality and accuracy of the data. A total of 55 surveys received could be attributed to one of the 14 strata. An additional 39 surveys received were not attributed to any of the 14 strata. The total number of surveys received was 94,2 more than the required 92. The criteria for stratification were: (1) inshore or offshore; (2) state of home port; (3) trans-shipping at sea or not; (4) fishing in the South Pacific or no $t$ when fishing offshore; and (5), the special category of vessels with PacFIN identifiers of "ZZZ" or "none", denoted "other." The data for trips of vessels fishing in the South Pacific was excluded, because the empirical study focused on the Pacific coast of North America.

Landings of albacore are primarily monitored via the processing facilities (canneries). That is, legal requirements dictate that financial transactions associated with commercially landed fish must be accounted for by a 'landing receipt.' Data from these receipts are processed and archived in a centralized data base (Pacific Fisheries Information Network or PacFIN) to provide U.S. albacore troll vessels' landings and exvessel prices. Additionally, the Western Fishboat Owners' Association (WFOA-albacore fishing industry organization) monitors all landings of albacore and maintains an independent data base. Final estimates of commercial landings of albacore are derived using both of the data bases above. It is generally believed that a 'small' amount of albacore are unaccounted for each year, given that some fishermen do not sell their fish to a cannery, but rather, directly to the public (say dockside from their vessel) and subsequently, may not document these sales.

U.S. effort data are obtained from log books filled out on a daily basis by U.S. albacore 
fishers while fishing. Historically, logbooks have not been required to be turned into NMFS, and thus each year only a sample of logbooks is collected from a subset of the entire population of fishermen, i.e., the sample is strictly non-random and based on logbooks that have been voluntarily submitted.

The opportunity cost of labor for an ordinary crewmember is the simple arithmetic mean for a number of blue collar labor categories (ranging from 6-10) that varied by coastal county of the state of the vessel's home port, and these data were obtained from the state labor departments for California, Oregon, and Washington. All crewmembers' opportunity cost also included three U.S. Bureau of Labor Statistics (BLS) categories. The opportunity cost of labor for the vessel's captain was the BLS category, "Bus, truck, and stationary engine mechanics," on the assumption that the captain has the skill and experience of working the vessel's engine. This skill is presumed readily transferable to other motor engines. This labor category is also one of the highest paid of the alternative possible occupations, which would reflect the captain's human capital comprising of not only mechanical skill, but organization and leadership skills and the quasi-rent the captain would receive for these skills. Squires et al. (2003) provide further details. 


\section{References}

Anderson, C. et al. 2008. Why Fishing Magnifies Fluctuations in Fish Abundance. Nature 452: 835-839.

Arrow, K. 1962. The Economic Implications of Learning by Doing. Review of Economic Studies 29: 155-173.

Arrow, K., P. Dasgupta, L. Goulder, G. Daily, P. Ehrlich, G. Heal, S. Levin, K-G Mäler, S. Schneider, D. Starrett, and B. Walker. 2004. Are We Consuming Too Much? Journal of Economic Perspectives 18(3): 147-172.

Baltagi, B. and J. Griffin. 1988. A General Index of Technical Change. Journal of Political Economy 96(1): 20-41.

Baltagi, B., J. Griffin, and D. Rich. 1995. The Measurement of Firm-Specific Indexes of Technical Change. Review of Economics and Statistics 77(4): 654-663.

Berck, P. 1995. Empirical Consequences of the Hotelling Principle in D. Bromley, ed., Handbook of Environmental Economics. Oxford: Oxford University Press, 202-221.

Blackorby, C., C., C.A.K. Lovell, and M.C. Thursby. 1976. Extended Hicks Neutral Technological Change. Economic Journal 86 (344): 845-852.

Brown, G. 2000. Renewable Natural Resource Management and Use without Markets Journal of Economic Literature 38(4): 875-914.

Chambers, R. 1988. Production Economics. Cambridge, U.K.: Cambridge University Press.

Clark, C.W. 1980. Towards a Predictive Model for Economic Regulation of Commercial Fisheries. Canadian Journal of Fisheries and Aquatic Sciences 37: 1111-1119.

Clark, C. 1990. Mathematical Bioeconomics: The Optimal Management of Renewable Resources, second edition New York: John Wiley and Sons.

Costello, C., S. Gaines, and S. Lynham. 2008. Can Catch Shares Prevent Fisheries Collapse? Science 321: 1678-1681.

d'Autume, Antoine and K. Schubert. 2008. Hartwick's Rule and Maximin Paths When the Exchaustible Resource Has an Amenity Value. Journal of Environmental Economics and Management.56(3): 260-274.

Dasgupta, P. 1982. The Control of Resources. Oxford: Basil Blackwell.

Dasgupta, P. 2008. Nature in Economics. Environmental and Resource Economics 39(1): $1-7$. 
Dasgupta, P. and G. Heal. 1979. Economic Theory and Exhaustible Resources. Cambridge: Cambridge University Press.

Dasgupta, P. and K.-G. Mäler, editors. 2004. The Economics of Non-Convex Ecosystems. Boston: Kluwer Academic Publishers.

Davis, L. R. E. Gallman and T. D. Hutchins. 1987. Technology, Productivity, and Profits: British-American Whaling Competition in the North Atlantic, 1816-1842. Oxford Economic Papers, New Series, 39(4): 738-759.

Debreu, G. 1951. The Coefficient of Resource Utilization. Econometrica 19)3): 273-292.

Denny, M. and M. Fuss. 1977. The Use of Approximation Analysis to Test for Separability and the Existence of Consistent Aggregates. American Economic Review 67: 404-418.

Diewert, E. 1976. Exact and Superlative Index Numbers. Journal of Econometrics 4: $115-145$.

FAO. 2006. World Review of Fisheries and Agriculture. Rome: Food and Agriculture Organization of the United Nations.

Farrell, M.J. 1957. The Measurement of Productive Efficiency: Journal of the Royal Statistical Society, Series A, General, 120, Part 3, 253-281.

Farzin, Y.H. 1995. Technological Change and the Dynamics of Resource Scarcity Measures. Journal of Environmental Economics and Management 29(1): 105-120.

Fox, K., R.Q. Grafton, T. Kompas, and N. Che. 2007. Capacity Reduction and Productivity: A Profit Decomposition for the Australian South East Trawl Fishery, in R. Curtis and D. Squires, editors, Fisheries Buybacks. Ames, Iowa: Blackwell Publishing.

Gordon, H.S. 1954. The Economic Theory of a Common Property Resource: The Fishery. Journal of Political Economy 62: 124-142.

Grafton, R.Q., T. Kompas, and R. Hilborn. 2007. Economics of Overexploitation Revisited. Science 318: 1601.

Hannesson, R. 1983. Bioeconomic Production Function in Fisheries: Theoretical and Empirical Analysis, Canadian Journal of Fisheries and Aquatic Sciences 40: 968-982.

Hannesson, R. 1993. Bioeconomic Analysis of Fisheries, Oxford: Blackwell Publishing. Heal, G. and W. Schlenker. 2008. Sustainable Fisheries. Nature 455: 1044-1045.

Huang, C. and T. Liu. 1994. Estimation of a Non-Neutral Stochastic Production Frontier. Journal of Productivity Analysis 5(2): 171-180. 
Jaffe, Adam B., Newell, Richard G., Stavins, Robert, N., 2003. Technological Change and the Environment. In: Mäler, K.-G. and J. Vincent,(Eds.), Handbook of Environmental Economics, Vol. 1. Elsevier Science, Amsterdam, pp. 461- 516.

Jensen, R. 2007. The Digital Provide: Information (Technology), Market Performance and Welfare in the South Indian Fisheries Sector. Quarterly Journal of Economics CXXII (3): 879-924.

Kirkley, J., D. Squires, and I. Strand. 1998. Characterizing Managerial Skill and Technical Efficiency in a Fishery. Journal of Productivity Analysis 9: 145-160.

Kirkley, J., C. Morrison Paul, S. Cunningham, and J. Catanzano. 2004. Embodied and Disembodied Technical Change in Fisheries: An Analysis of the Sète Trawl Fishery, 1985-1999. Environmental and Resource Economics 29: 191-217.

McAusland, C. 2005. Learning By Doing in the Presence of an Open Access Renewable Resource: Is Growth Sustainable? Natural Resource Modeling 18(1): 41-68.

McDaniel, J.D., P. R. Crone, and E. Dorval 2006. Critical Evaluation of Important Time Series Associated With Albacore Fisheries (United States, Canada, and Mexico) of the Eastern North Pacific Ocean (2006). ISC/06/ALBWG/09, Working document submitted to the ISC Albacore Working Group Workshop, November 28-December 5, 2006, Shimizu, Shizuoka. Japan.

Murphy, K. and R. Topel. 1985. Estimation and Inference in Two-Step Econometric Models. Journal of Business and Economic Statistics3(4): 370-379.

Murray, J. 2007. Constrained Marine Resource Management. Unpublished Ph.D. Dissertation, Department of Economics, University of California San Diego.

Park, B.U., Sickles, R.C., Simar, L., 2003. Semiparametric Efficient Estimation of AR(1) Panel Data Models. Journal of Econometrics 117: 279-309.

Pizer, W.A. and D. Popp. 2007. Endogenizing Technological Change: Matching Empirical Evidence to Modeling Needs. RFF DP 07-11, Resources for the Future, Washington, D.C.

Rosenberg, N. 1982. Learning by Using, in N. Rosenberg, ed., Inside the Black Box: Technology

Ruttan, V. 2001. Technology, Growth, and Development: An Induced Innovation Perspective. Oxford: Oxford University Press.

Schaefer, M.B. 1957. A Study of the Dynamics of the Fishery for Yellowfin Tuna in the Eastern Tropical Pacific Ocean. Bulletin of the Inter-American Tropical Tuna 
Commission 2: 247-285.

Scott, Anthony D. 1955. The Fishery: The Objectives of Sole Ownership. Journal of Political Economy 63: 116-124.

Schmidt, P. and R. Sickles. 1984. Production Frontiers and Panel Data. Journal of Business and Economic Statistics 2: 367-374.

Sickles, R. 2005. Panel Estimators and the Identification of Firm-Specific Efficiency Levels in Parametric, Semi-Parametric and Non-Parametric Settings. Journal of Econometrics 126: 305-334.

Simpson, R.D., M. Toman, R. Ayres, eds. 2005. Scarcity and Growth Revisited: Natural Resources and the Environment in the New Millenium. RFF Press.

Smith, V.K. 1972. The Implications of Common Property Resources for Technical Change European Economic Review 3: 469-479.

Smith, V.K. and J. Krutilla. 1982. Reformulating the Role of Natural Resources in Economic Models in V,K, Smith and J.V. Krutilla, eds,. Explorations in Natural Resource Economics. Baltimore: Johns Hopkins University Press.

Squires, D. 1987. Fishing Effort: Its Testing, Specification, and Internal Structure in Fisheries Economics and Management. Journal of Environmental Economics and Management 14(3): 262-287.

Squires, D. 1992. Productivity Measurement in Common Property Resource Industries, Rand Journal of Economics 23(2): 221-236.

Squires, D., Kirkley, J. \& Tisdell, C.A. 1995. Individual Transferable Quotas as a Fisheries Management Tool. Reviews in Fisheries Science. 3(2), 141-169.

Squires, D., S. Herrick, Jr., D. Dealy, AFRF, and D. Colpo. 2003. Cost-and-Earnings Survey of the West Coast Albacore Troll Fleet, 1998-1999. National Marine Fisheries Service, Southwest Fisheries Science Center Administrative Report LJ-03-01, La Jolla, California.

Vestergaard, N., F. Jensen and H.P. Jørgensen. 2005. Sunk Cost and Entry-Exit Decisions under Individual Transferable Quotas: Why Industry Restructuring Is Delayed. Land Economics, 81(3), 363-378.

Van Kooten, G. and E. Bulte. 2000. The Economics of Nature: Managing Biological Assets. Blackwell Publishers.

Whitmarsh, D. 1990. Technological Change and Marine Fisheries Development. Marine Policy 14(1): 15-22.

Worm, B. et al. 2006, Impacts of Biodiversity Loss on Ocean Ecosystem Services. 
Science 314, 787-790. 
Table 1. Expressions for Yield, Stock and Effort at maximum sustainable yield, optimal and open access with output-augmenting technical change and static model.

\begin{tabular}{|c|c|c|c|c|c|c|}
\hline & MSY & $\mathrm{MSY}^{\mathrm{TE}, \mathrm{t}}$ & Optimal & Optimal $^{\mathrm{TE}, \mathrm{t}}$ & Open Access & Open Access ${ }^{T E, t}$ \\
\hline $\begin{array}{l}\text { Yield } \\
\text { (Y) }\end{array}$ & $\frac{r K}{4}$ & $\frac{r K}{4}$ & $\frac{r K}{4}\left(1-\left(\frac{c}{p q K}\right)^{2}\right)$ & $\frac{r K}{4}\left(1-\left(\frac{c}{p q K e^{\lambda t-\mu(t, z)}}\right)^{2}\right)$ & $\frac{c r}{p q}\left(1-\frac{c}{p q K}\right)$ & $\frac{c r}{p q e^{\lambda t-\mu(t, Z)}}\left[1-\frac{c}{P K q e^{\lambda t-\mu(t, Z)}}\right.$ \\
\hline $\begin{array}{l}\text { Stock } \\
\text { (S) }\end{array}$ & $\frac{K}{2}$ & $\frac{K}{2}$ & $\frac{K}{2}\left(1+\frac{c}{p q K}\right)$ & $\frac{K}{2}\left(1+\frac{c}{p q K e^{\lambda t-\mu(t, z)}}\right)$ & $\frac{c}{p q}$ & $\left.\frac{c}{p q e^{\lambda t-\mu(t, z)}}\right)$ \\
\hline $\begin{array}{l}\text { Effort } \\
\text { (E) }\end{array}$ & $\frac{r}{2 q}$ & $\frac{r}{2 q e^{\lambda t-\mu(t, z)}}$ & $\frac{r}{2 q}\left(1-\frac{c}{p q K}\right)$ & $\frac{r}{2 q e^{\lambda t-\mu(t, z)}}\left(1-\frac{c}{p q K e^{\lambda t-\mu(t, z)}}\right)$ & $\frac{r}{q}\left(1-\frac{c}{p q K}\right)$ & $\frac{r}{q e^{\lambda t-\mu(t, Z)}}\left[1-\frac{c}{P K q e^{\lambda t-\mu(t, Z)}}\right.$ \\
\hline
\end{tabular}


Table 2. Expressions for optimal Yield, Stock and Effort with output-augmenting technical change and dynamic model.

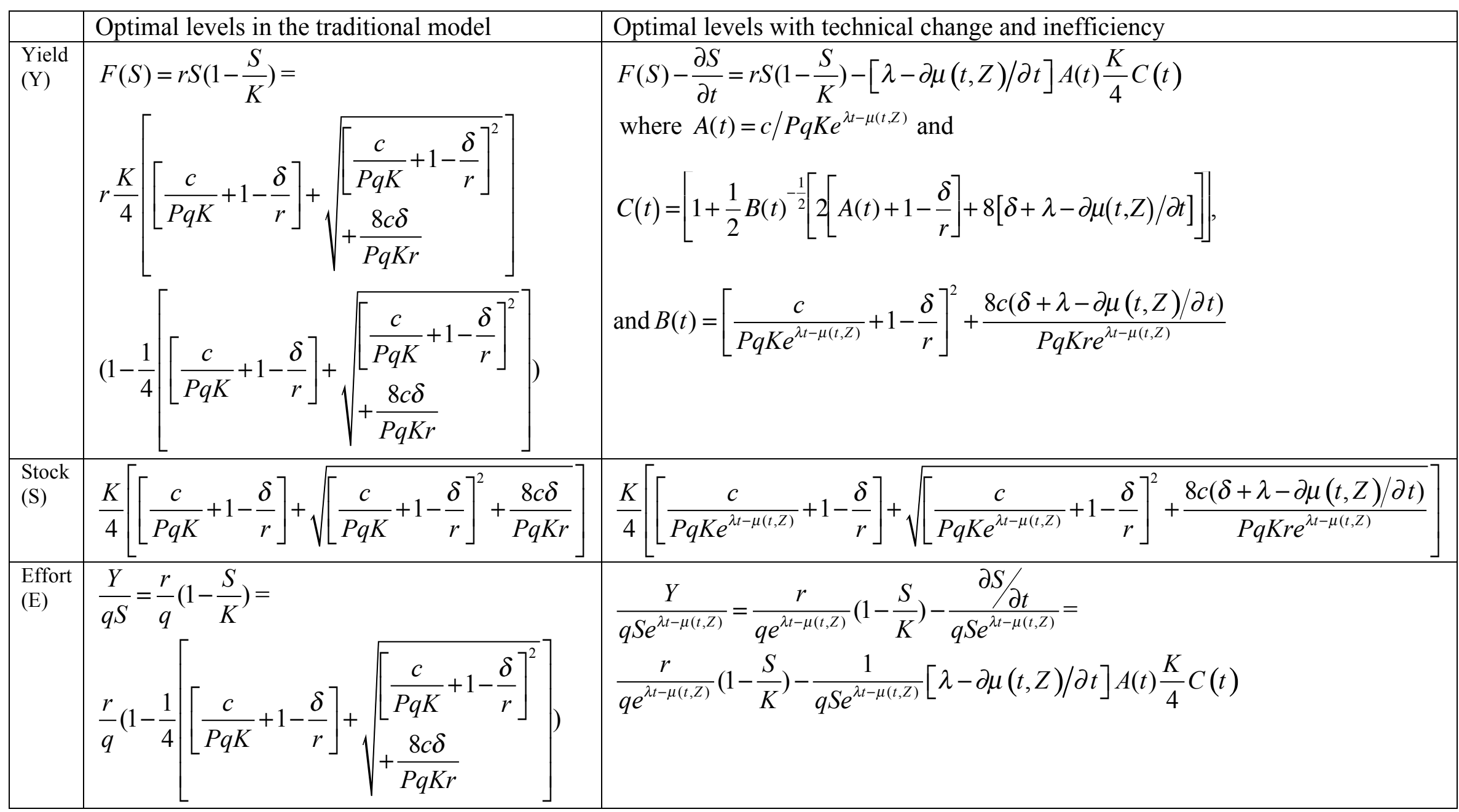


Table 3. Summary Statistics of the Data

\begin{tabular}{|l|r|r|r|r|}
\hline Category & Mean & St. Deviation & Minimum & \multicolumn{1}{c|}{ Maximum } \\
\hline U.S. Catch (mt) & $8,750.86$ & $4,316.87$ & $1,845.00$ & $16,938.35$ \\
\hline U.S. Days Fished & $24,226.38$ & $10,195.95$ & $9,146.24$ & $44,774.79$ \\
\hline U.S. Vessel Numbers & 732.00 & 367.19 & 172.00 & $1,837.00$ \\
\hline U.S. Composite Effort Tornqvist Index & 0.5164 & 0.2164 & 0.1860 & 1.00 \\
\hline U.S. Variable Input (Days Fished) Cost Share & 0.73 & 0.14 & 0.50 & 0.92 \\
\hline U.S. Capital Cost Share & 0.27 & 0.14 & 0.08 & 0.50 \\
\hline Canada Catch (mt) & $3,410.38$ & $2,416.83$ & 139.00 & $7,856.00$ \\
\hline Canada Days Fished & 878.35 & 984.10 & 95.88 & $3,371.29$ \\
\hline Canada Vessel Numbers & 187.00 & 76.09 & 45.00 & 295.00 \\
\hline Canada Composite Effort Tornqvist Index & 2.6445 & 1.9338 & 0.6110 & 7.4646 \\
\hline Canada Variable Input (Days Fished) Cost Share & 0.81 & 0.11 & 0.67 & 0.92 \\
\hline Canada Capital Cost Share & 0.19 & 0.11 & 0.08 & 0.33 \\
\hline Price of Albacore (US\$/mt) & $2,852.24$ & 505.70 & 1975.45 & $3,983.32$ \\
\hline Cost per day (US\$/day) & 1268.48 & 255.26 & 936.90 & 1978.52 \\
\hline Biomass from International Stock Assessment (mt) & $170,956.98$ & $25,522.07$ & $124,684.19$ & $22,5743.85$ \\
\hline
\end{tabular}

Note: Monetary values in US\$2001. 
Table 4. Parameter Estimates of Linear Time Trend Model with Tornqvist Index of Effort, 1981-2006

\begin{tabular}{|l|l|l|l|l|l|l|}
\hline & \multicolumn{4}{|l|}{ Effort Coefficient not Restricted } & \multicolumn{3}{l|}{ Effort Coefficient $=1$} \\
\hline Parameter & Estimate & St. Error & t-statistic & Estimate & St. Error & t-statistic \\
\hline Constant & -2.8507 & 8.4033 & 0.3392 & -7.7721 & 10.4620 & -0.7490 \\
\hline Dummy Canada & -1.8754 & 0.5974 & -3.1393 & -2.7323 & 0.2920 & -9.3580 \\
\hline Effort & 0.1245 & 0.1301 & 0.9572 & 1.000 & & \\
\hline Biomass & 0.9727 & 0.6956 & 1.3984 & 1.4161 & 0.8752 & 1.6180 \\
\hline Trend & 0.0446 & 0.0243 & 1.8322 & 0.0427 & 0.0210 & 2.0287 \\
\hline Rho & 0.7572 & 0.1416 & 5.4025 & 0.3336 & 0.1519 & 2.1958 \\
\hline$R^{2}$ & 0.808262 & & & 0.827605 & & \\
\hline Log-Likelihood & -29.1723 & & & -42.1681 & & \\
\hline
\end{tabular}

Note: Number of observations $=43$. Maximum likelihood estimation with

Correction for first-order serial correlation. Cobb Douglas functional form with linear time trend. 
Table 5. Parameter Estimates of General Index of Technical Change Model with Tornqvist Index of Effort, 1981-2006

\begin{tabular}{|l|l|l|l|}
\hline Parameter & Estimate & St. Error & t-statistic \\
\hline Constant & 36.2217 & 86.9674 & .416497 \\
\hline Dummy Canada & -2.77949 & 0.265188 & -10.4812 \\
\hline Effort & 1.000 & & \\
\hline Biomass & -2.24909 & 7.28238 & -.308840 \\
\hline Rho & .609177 & .121853 & 4.99927 \\
\hline D1983 & -.070812 & .330995 & -.213937 \\
\hline D1984 & .474335 & .948242 & .500225 \\
\hline D1985 & .477752 & .584542 & .817311 \\
\hline D1986 & .178382 & .603761 & .295451 \\
\hline D1987 & -.470339 & .871398 & -.539752 \\
\hline D1988 & .162001 & 0.555134 & .291823 \\
\hline D1989 & -.738228 & .945343 & -.780910 \\
\hline D1990 & -.710823 & 1.60617 & -.442557 \\
\hline D1991 & -.894899 & .832313 & -1.07520 \\
\hline D1992 & -.074155 & 1.47201 & -.050377 \\
\hline D1993 & -.549851 & 1.14332 & -.480923 \\
\hline D1994 & .175547 & .684737 & .256371 \\
\hline D1995 & .586890 & 1.15904 & .506358 \\
\hline D1996 & 2.25675 & 2.84855 & .792245 \\
\hline D1997 & 1.07411 & 2.80150 & .383406 \\
\hline D1998 & 1.92104 & 1.74271 & 1.10233 \\
\hline D1999 & 1.61324 & 2.03451 & .792937 \\
\hline D2000 & .382128 & .697466 & .547881 \\
\hline D2001 & .836831 & .694556 & 1.20484 \\
\hline D2002 & 1.08690 & 1.17526 & .924817 \\
\hline D2003 & 1.28201 & .598456 & 2.14220 \\
\hline D2004 & 1.44485 & 1.58139 & .913657 \\
\hline D2005 & .704940 & 1.72686 & .408220 \\
\hline D2006 & 2.13323 & 1.95737 & 1.08984 \\
\hline & & & \\
\hline
\end{tabular}

Note: Number of observations $=43$. Unbalanced panel data, U.S. 19812006, Canada 1990-2006. Cobb Douglas functional form with general index of technical change and effort coefficient $=1$.

$R^{2}=0.948$. Log-likelihood $=-16.8179$. Std. error of regression $=0.602515$.

Standard Errors computed from heteroscedastic-consistent matrix (Robust-White) 
Table 6. Parameter Estimates of Translog Effort Aggregator Function

\begin{tabular}{|l|l|l|l|l|l|l|l|l|l|}
\hline & \multicolumn{3}{|l|}{ No Restrictions } & \multicolumn{3}{l|}{ Effort Coefficient= 1 } & \multicolumn{2}{l|}{ Effort and Stock Coefficients = 1 } \\
\hline Parameter & Estimate & $\begin{array}{l}\text { St. } \\
\text { Error }\end{array}$ & t-statistic & Estimate & $\begin{array}{l}\text { St. } \\
\text { Error }\end{array}$ & $\begin{array}{l}\text { t- } \\
\text { statistic }\end{array}$ & Estimate & St. Error & t-statistic \\
\hline Constant & 0.5157 & 0.1543 & 3.34 & 0.4907 & 0.1422 & 3.45 & 0.4961 & 0.1262 & 3.93 \\
\hline $\begin{array}{l}\text { Dummy } \\
\text { Canada }\end{array}$ & -0.2318 & 0.1164 & -1.99 & -0.2367 & 0.0877 & -2.70 & -0.2346 & 0.0840 & -2.79 \\
\hline $\begin{array}{l}\text { Days } \\
\text { Fished }\end{array}$ & 0.0093 & 0.0091 & 1.02 & 0.0072 & 0.0093 & 0.78 & 0.0062 & 0.0086 & 0.72 \\
\hline $\begin{array}{l}\text { Number } \\
\text { of Vessels }\end{array}$ & 0.0026 & 0.0146 & 0.18 & 0.0078 & 0.0099 & 0.79 & 0.0089 & 0.0087 & 1.02 \\
\hline Rho & 1.033 & 0.0328 & 31.47 & 1.0325 & 0.0304 & 34.01 & 1.0325 & 0.0312 & 33.08 \\
\hline$R^{2}$ & 0.9171 & & & 0.9159 & & & 0.9158 & & \\
\hline
\end{tabular}

Full information maximum likelihood estimation with first-order serial correlation correction joint with catch frontier. 
Table 7. Parameter Estimates of Catch Frontier

\begin{tabular}{|l|l|l|l|l|l|l|l|l|l}
\hline & \multicolumn{2}{|l}{ No Restrictions } & \multicolumn{3}{l|}{ Effort Coefficient = 1 } & \multicolumn{2}{l}{ Effort and Stock Coefficients = 1 } \\
\hline Parameter & Estimate & $\begin{array}{l}\text { St. } \\
\text { Error }\end{array}$ & $\begin{array}{l}\text { t- } \\
\text { statistic }\end{array}$ & Estimate & $\begin{array}{l}\text { St. } \\
\text { Error }\end{array}$ & $\begin{array}{l}\text { t- } \\
\text { statistic }\end{array}$ & Estimate & St. Error & t-statistic \\
\hline Constant & -6.1134 & 7.9111 & -0.77 & -6.0064 & 8.2430 & -0.73 & -11.9193 & 0.6438 & -18.52 \\
\hline $\begin{array}{l}\text { Dummy } \\
\text { Canada }\end{array}$ & -4.4927 & 2.4217 & -1.86 & -3.4666 & 1.6889 & -2.05 & -3.2852 & 1.7343 & -1.89 \\
\hline $\begin{array}{l}\text { Dummy } \\
\text { Canada*Effort }\end{array}$ & 1.6931 & 0.9160 & 1.85 & 1.2529 & 0.2319 & 5.40 & 1.1934 & 0.2428 & 4.92 \\
\hline Effort & 0.7784 & 0.3415 & 2.28 & 1.0000 & & & 1.0000 & & \\
\hline Biomass & 0.6280 & 0.7446 & 0.84 & 0.4952 & 0.6980 & 0.71 & 1.0000 & & \\
\hline Trend & 0.0389 & 0.0121 & 3.22 & 0.3896 & 0.0116 & 3.36 & 0.0356 & 0.0111 & 3.21 \\
\hline Likelihood & 57.6471 & & & 57.3455 & & & 57.3455 & & \\
\hline$R^{2}$ & 0.8278 & & & 0.8333 & & & 0.8331 & & \\
\hline
\end{tabular}

Note: Number of observations $=43$. Full information maximum likelihood estimation jointl with effort aggregator function.

Table 8. Parameter Estimates of Two-Factor Learning Curve, 1981-2006

\begin{tabular}{|l|l|l|l|}
\hline Parameter & Estimate & St. Error & t-statistic \\
\hline Constant & 6.60755 & 1.38302 & 4.77762 \\
\hline Dummy Canada & 1.26423 & .612536 & 2.06393 \\
\hline Cumulative Catch & .108867 & .047989 & 2.26857 \\
\hline Biomass & -.125511 & .110088 & -1.14010 \\
\hline Rho & .983322 & .015283 & 64.3390 \\
\hline
\end{tabular}

Note: Number of observations $=43$. Maximum likelihood estimation with correction for first-order serial correlation. $R^{2}=0.957$. Log likelihood $=42.2637$. Std. error of regression $=.140768$. 
Figure 5. Optimum stock size over a 150-year time horizon

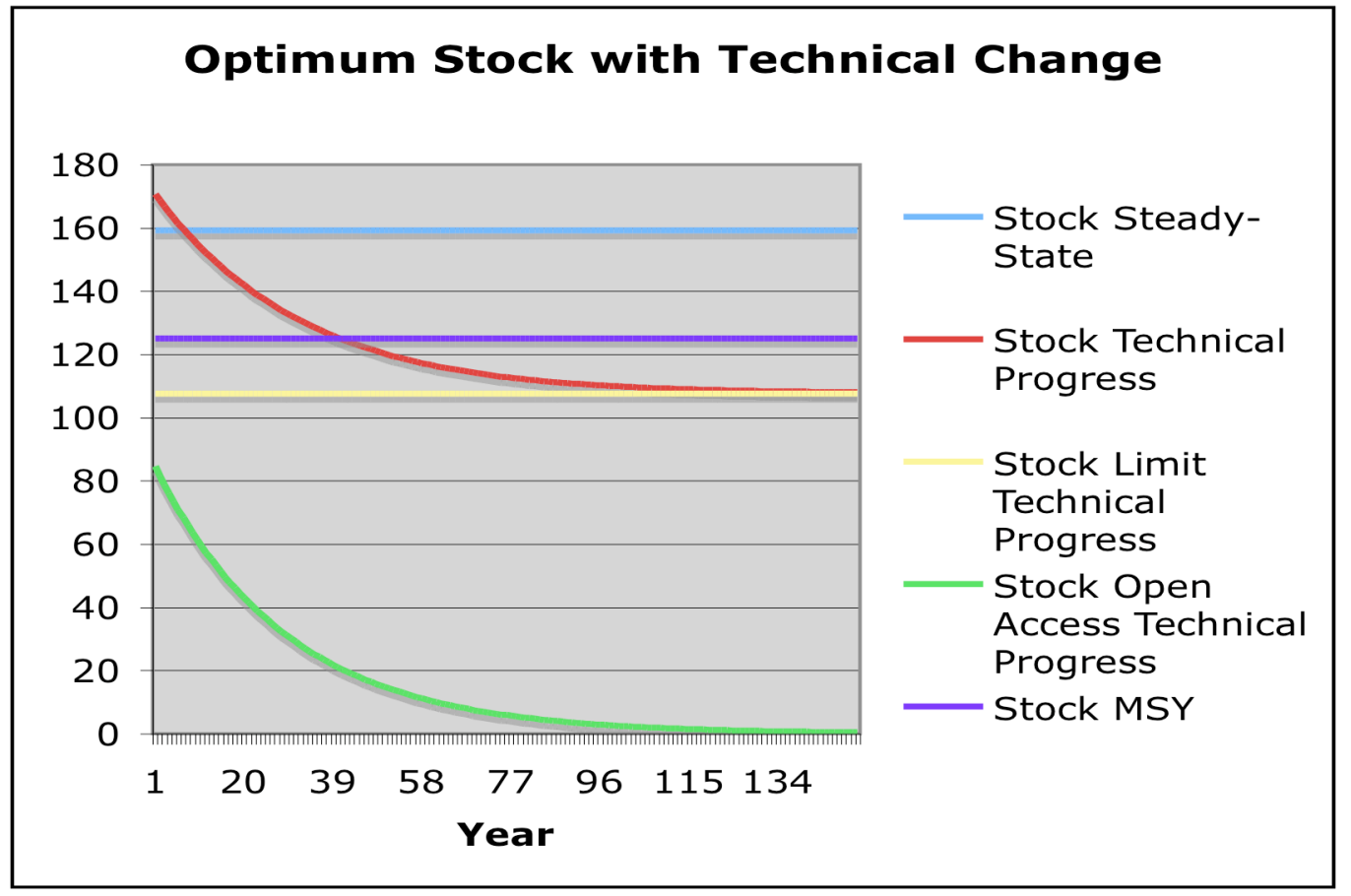

Figure 6. Optimum yield over a 150-year time horizon

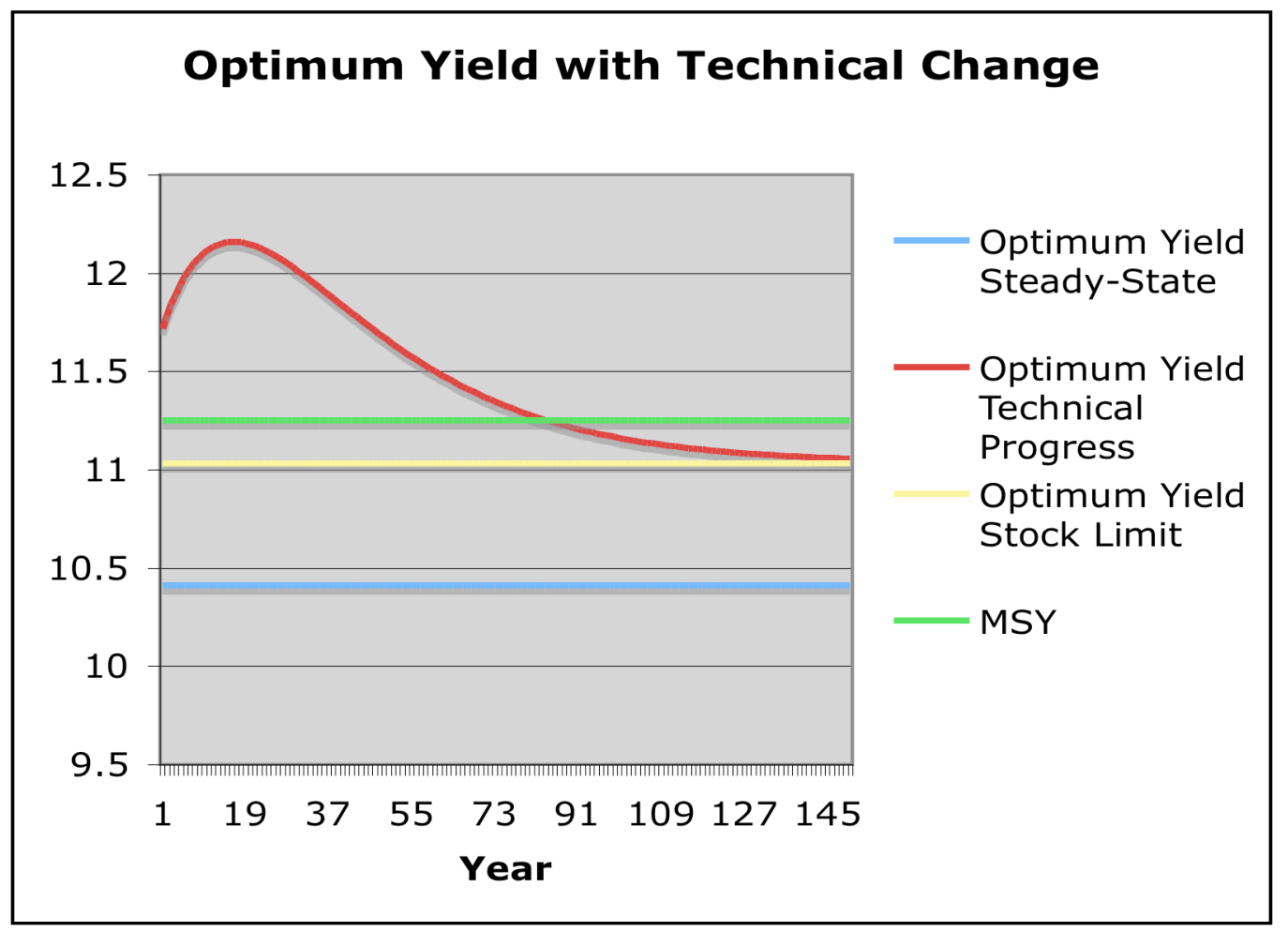


Figure 7. Marginal stock and technology effects in modified Golden Rule

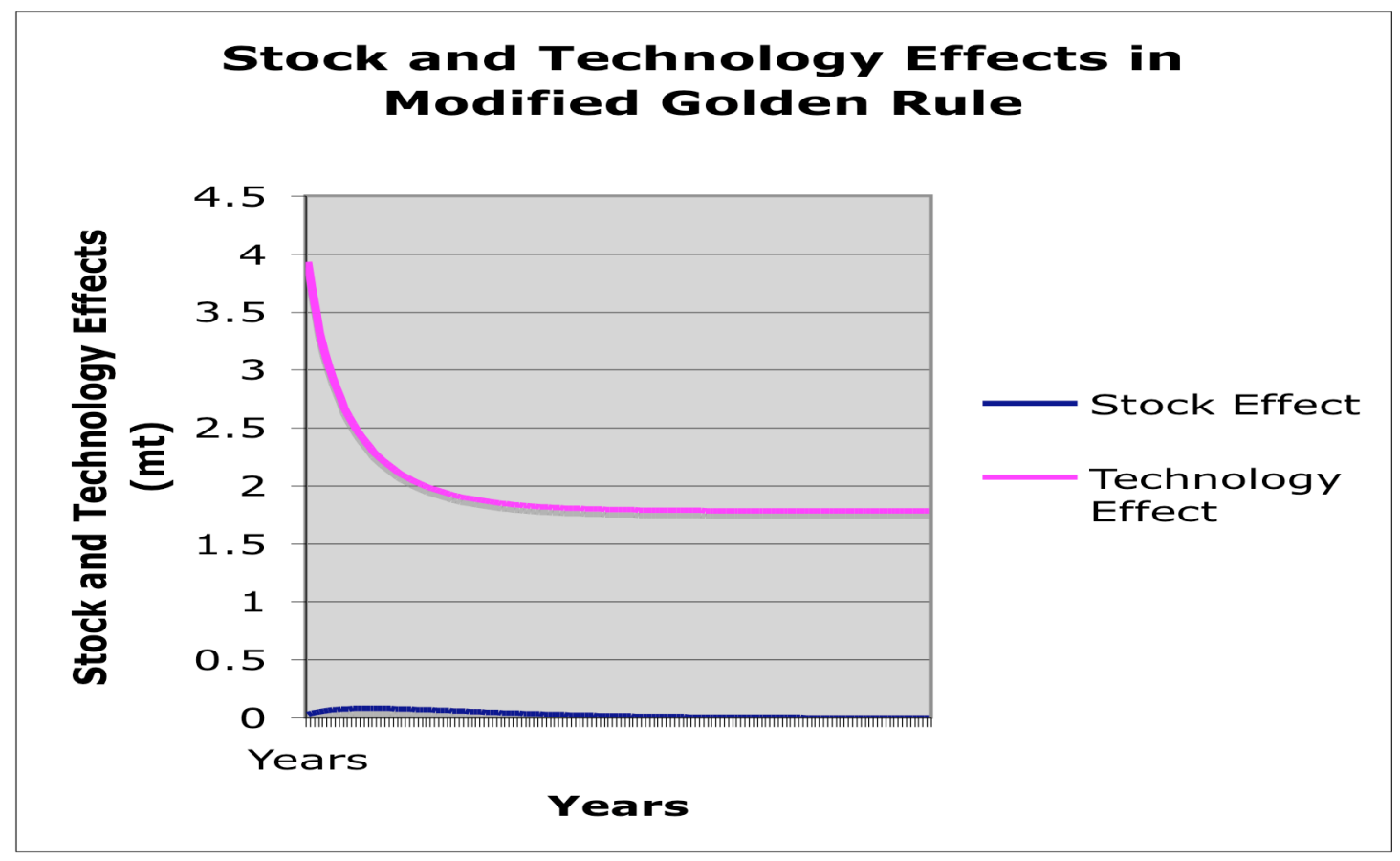

Figure 8. Optimum resource stocks with technical change and schooling

\section{Optimum Stock with Technical Change and Schooling}

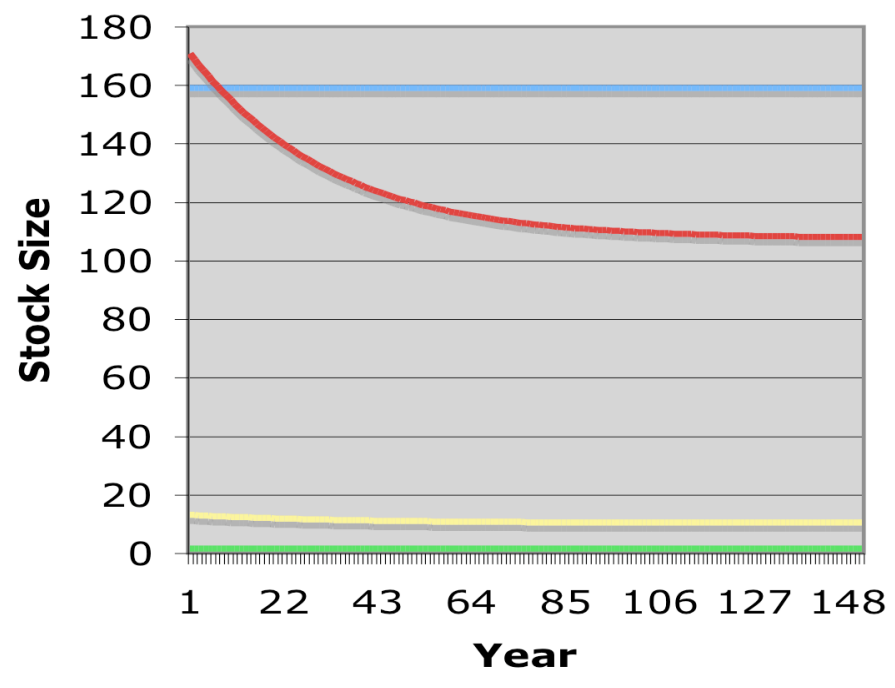

Stock SteadySteady State

Stock Technical Progress Exp = 1

Stock Technical Progress $\mathrm{Exp}=$ 0.5

Stock Technical Progress Exp = 0.1 
Figure 9. Optimum Tax

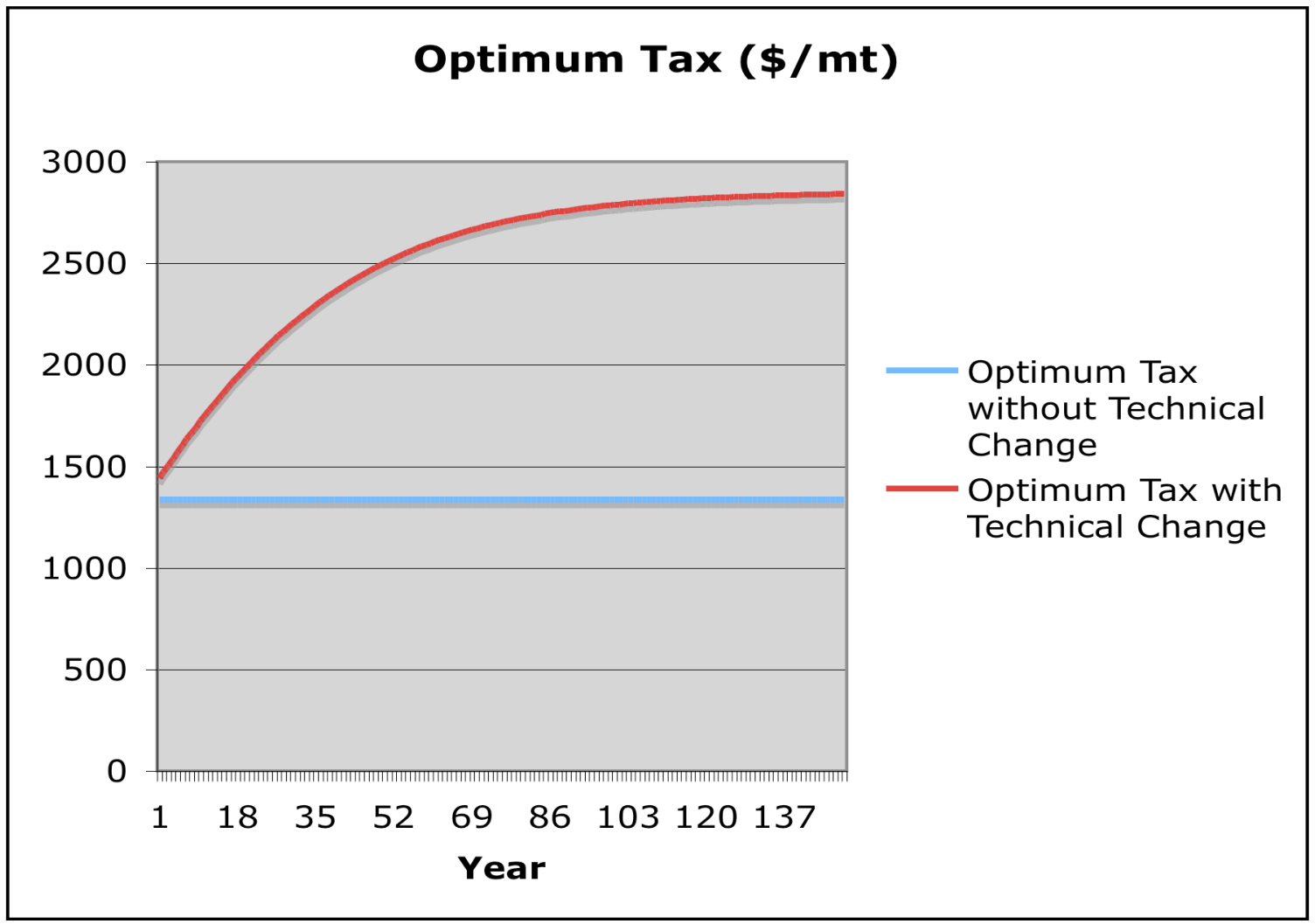

Figure 10. Static Stock Externality, 1981-2006 


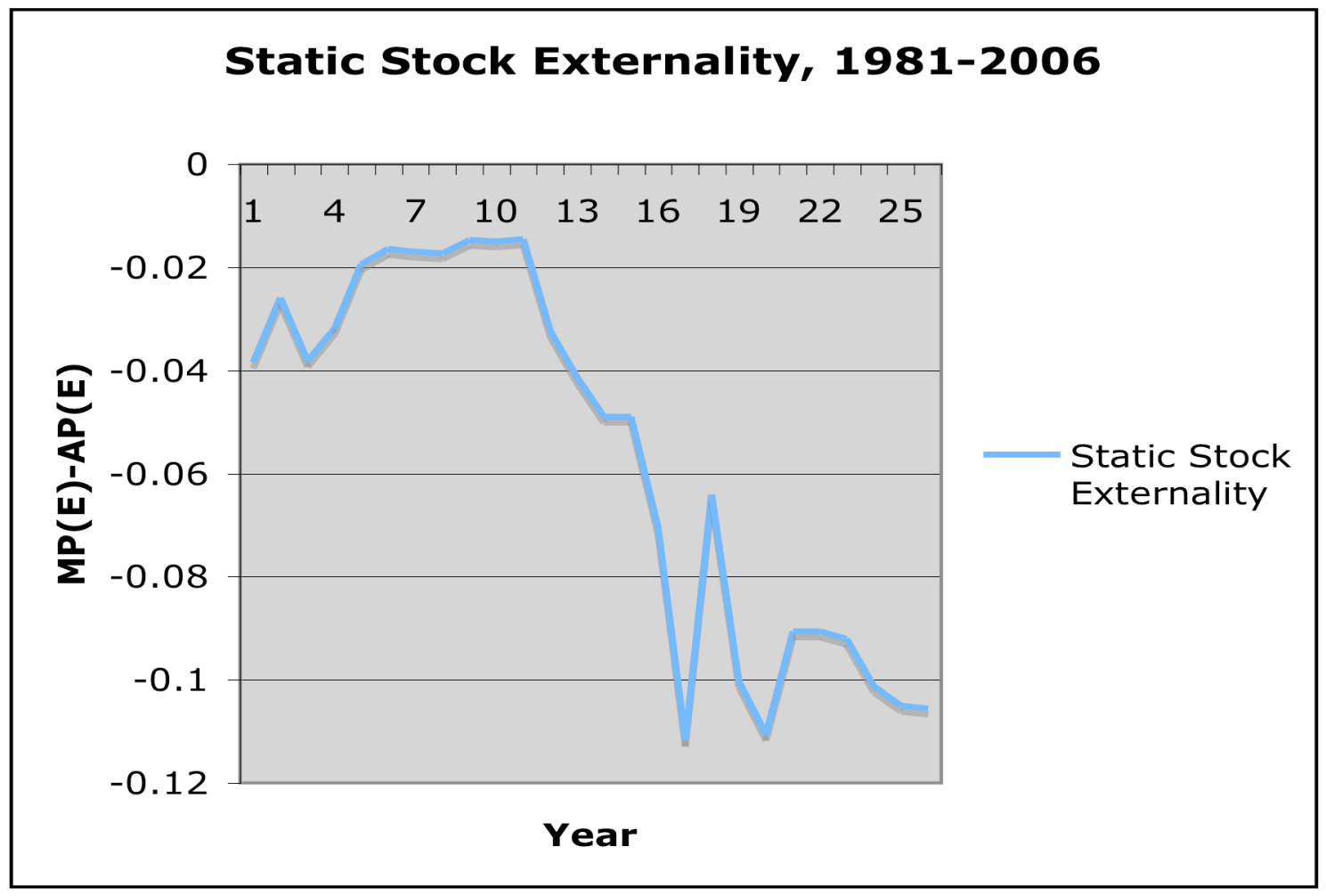




\section{Endnotes}

${ }^{1}$ See, for example, the following representative classics of renewable resource economics: Gordon (1954), Scott (1955), Dasgupta and Heal (1979), Dasgupta (1982), Clark (1990), and Hannesson (1993). Dasgupta (1982) explicitly holds technology constant. Brown (2000), in an authoritative survey, mentions in passing that optimal technology is assumed fixed in normative models. There is also a literature on trade, renewable resources, economic growth, and technical change introduced by Brander and Taylor (1998), reviewed by McAusland (2005), but it is not germane to the present discussion on normative utilization of common renewable resources.

${ }^{2}$ Whitmarsh (1980) and Ruttan (2001) qualitatively discussed technical change with common renewable resources, with Whitmarsh stressing transferable property rights in outputs, a conclusion also reached by Murray (2007) and this paper. Squires (1992) and a subsequent positive economics literature evaluated productivity growth when explicitly accounting for the resource stock. Jensen (2007) examined the impact of cell phones on artisanal fishers. Technical inefficiency in a positive framework was introduced by Hannesson (1983) through a deterministic frontier and extended to the stochastic frontier by Kirkley et al. (1998), but has not yet been introduced into a normative framework.

${ }^{3}$ Scale efficiency arises when price equals marginal cost. In the standard bioeconomic model, assumptions of homothetic separability between inputs and outputs and joint production are imposed to form an aggregate output and an aggregate input (Squires 1987). Consequently, profit or rent efficiency in the renewable resource economics literature -- the traditional Pareto optimum or Maximum Economic Yield -- reduces to only scale efficiency, and technical efficiency and allocative efficiency for multiple inputs and for multiple outputs are overlooked as sources of economic efficiency. This paper introduces technical efficiency, but allocative inefficiency in the second stage of production is inherently prohibited because of the input-output separability.

${ }^{4}$ This classic Gordon-Schaefer model specifies a composite input, fishing effort, with an exponent of one, and a composite output, catch, a composite measure of resource abundance, biomass, also with an exponent of one, static technology, and no allowance for technical inefficiency. Marginal costs increasing in the harvest rate require an exponent less than one for effort. Subsequent refinements introduce demographic features of the population (age structure), non-instantaneous entry and exit, investment, and further features (Clark 1990, Hannesson 1993, Brown 2000), but our focus is on analytically developing the modified fundamental equation of renewable resource economics to clearly demonstrate the effect of changes in technology and technical efficiency. The specification of a classic Gordon-Schaefer model leads to an optimization model is linear in the control Y, but the optimal stock and harvest rate is nonetheless not linear, and instead varies continuously with changes in technology and technical efficiency. Nonlinearity in E yields a marginal cost function that is non-linear in Y, but analytical solutions are not possible for the augmented fundamental equation of renewable resource economics, and the fundamental point of this paper is unchanged.

${ }^{5}$ The main omissions are embodied technical change, endogenous technical change, 
jump-diffusion (diffusion is currently incorporated by technical inefficiency), costs nonlinear in the control variable (following from non-linear effort), and stochasticity, all subjects of future research and given our focus on the classical renewable resource model based on Gordon (1954) and Schaefer (1957). As we discuss below, the majority of technical change in fishing industries is likely to be autonomous rather than endogenous because of research and development activities by firms. We leave for future work analysis, in the presence of weak or nonexistent resource policies, of investments in the development and diffusion of new environmentally beneficial technologies (which are likely to be less than would be socially desirable). We further leave for the future the analysis of the impact of positive knowledge and adoption spillovers and information problems that can affect innovation incentives, and in general knowledge market failures.

${ }^{6}$ Rapid advancements in fishing technologies led to increased fishing pressure on all fish stocks in the $20^{\text {th }}$ century. Mechanical power for vessels replaced sail power, which allowed the development of new types of gear and substantially larger vessels and gear and the exploitation of fish stocks in previously inaccessible ocean locations and depths and at substantially higher levels of productivity. Synthetic materials for gear and the power block in the 1950s were also critical. Vessel electronics, such as sonar, chromoscopes, satellite imaging, cell phones, and GPS, help communications, navigation, locate fish, monitor gear performance while fishing, and develop markets. The vast majority of large, industrial-scale vessels were constructed between about 1960-1990. Local traditional knowledge has in many instances been succeeded by the technologybased knowledge of modern electronic equipment, communications, and satellites.

${ }^{7}$ The usual regularity conditions for a production function are assumed (Dasgupta 1982, p. 125): a single-valued continuous function with continuous first and second partial derivatives; $0=f\left(S_{t}, 0\right)=f\left(0, E_{t}\right)$; positive first partial derivatives $\left(\partial Y_{t} / \partial S_{t}>0, \partial Y_{t} / \partial E_{t}>0\right)$; concavity in $S_{t}$ and quasi-concavity in $E_{t}$, so that for the own second partial derivatives $\left(\partial^{2} Y_{t} / \partial S_{t}^{2}<0, \partial^{2} Y_{t} / \partial E_{t}^{2} \leq 0\right)$; and a non-negative mixed second partial derivative $\partial^{2} Y_{t} / \partial S_{t} \partial E_{t}=\partial^{2} Y_{t} / \partial E_{t} \partial S_{t} \neq 0$, where symmetry is assumed. $Y_{t}=f\left(S_{t}, E_{t}\right)$ is bounded from above by the size of the fish stock. Crowding or congestion of vessels occurs when $\partial Y_{t} / \partial E_{t}<0$ and the opposite when $\partial Y_{t} / \partial E_{t}>0$ (Dasgupta and Heal 1979) and $\partial Y_{t} / \partial S_{t} \leq 0$ is expected in a stock-flow production technology.

${ }^{8}$ The authors are grateful to Pat Tomlinson for this definition. q converts, in a Hick'sneutral manner, the level of $E_{t}$ to the proportion of $S_{t}$ removed and captures changes in technology, technical efficiency, the environment, and other factors not captured by $E_{t}$.

${ }^{9}$ Output-oriented technical efficiency measures the potential increase in output given the current level of input. In fishing industries, it captures skipper skill, including the ability to find and harvest fish, catching up to the best-practice production frontier that is shifting due to technical change, and the impact of some regulations designed to lower technical efficiency to reduce fishing mortality (Kirkley et al. 1998). When technical inefficiency is due to an expanding frontier - especially with learning by doing, rates of 
adoption and hence gains in technical efficiency may diffuse more slowly than when regulatory induced. Conversely, the competitive pressures induced by market failure with common resources and incomplete property rights could hasten the pace of diffusion (Smith 1972, Ruttan 2001).

${ }^{10}$ Squires (1992) and Arrow et al. (2006) analyze the importance of disentangling changes in the natural resource stock from changes in technology when evaluating changes in productivity. Disembodied technical change may easily predominate over embodied technical change, as found by Kirkley et al. (2004) in the only positive analysis of both types of technical change in a renewable resource, in this case a fishery.

${ }^{11}$ Technological change $A(t)$ in the form of process innovations affecting $E_{t}$ in a production function of the form $Y_{t}=A(t) F\left(S_{t}, E_{t}\right)$ is both Hick's-neutral and output augmenting (Lau 1978, p. 204). Letting $A(t)=q \lambda(t)=q e^{\lambda t}$, where the latter term denotes a constant rate of technical change $\lambda$, denotes output-augmenting technical change in the Graham-Schaefer production frontier $Y_{t}=q e^{\lambda t} S_{t} E_{t}=q S_{t} E_{t} e^{\lambda t}$ (ignoring technical inefficiency). Because of the weak homothetic input separability allowing the formation of a consistent composite input $E_{t}$ (and usually the stronger condition of input-output --and hence strong -- separability when there are multiple outputs such as species or sizes or fish), and the linear homogeneity of the input aggregator function required for a consistent composite input index, biased technical change among the input pairs comprising $E_{t}$ in a first stage of production is impossible, i.e. technical change is implicit Hick's neutral among all input pairs comprising E (under implicit Hicks input neutrality, the marginal rate of substitution between any inputs is independent of the technology index $\mathrm{t}$, and the resource stock $B_{t}$ ), and changes in the scale of production do not affect input ratios. The Graham-Schaefer form $Y_{t}=A(t) S_{t} E_{t}$ is strongly separable in $E_{t}$, which provides Hick's (and Harrod and Solow) neutrality for $E_{t}$, and which Blackorby, Lovell, and Thursby (1976) call extended Hick's-neutral technological change (allowing a multiplicative decomposition of the production function into one term involving input variables only and another involving the state-of-technology variable only and is expansion-path-preserving; extending this definition to an independent resource stock is straightforward). Moreover, when the aggregator function of individual inputs comprising $E_{t}$ is linear homogeneous, as with the Graham-Schaefer production frontier, factor-augmenting technical change that equally augments each input comprising $E_{t}$ is equivalent to output-augmenting technical change (cf. Thirtle and Ruttan 1987, pp. 1314).

${ }^{12}$ Interest in the sources of neutral or biased technical change could be accommodated by replacing the time-oriented terms described above with one or more proxy measures $(\mathrm{H})$ for proposed sources of technical change. This is one way of specifying embodied technical change, but faces potential omitted variable bias.

${ }^{13}$ We develop this discussion heuristically rather than through a formal model of learning by doing, which is beyond the scope of this paper's focus, although we estimate a twofactor learning curve in the empirical analysis. See McAusland (2005) for a formal model 
of learning by doing with renewable natural resources but with a focus on growth of an economy. We further abstract from incentives to adopt technology due to the state of property rights and other factors.

14 The nature and scale of fisheries production makes it difficult to restrict information about new technology or practices. Moreover, even the largest vessels or fishing firms are relatively small units and are not able to capture more than a small share of the gains from inventive activity. Under the incomplete or absent use rights characterizing most fishing industries, the private benefits to research and development to advance the state of technology cannot be captured by private firms for any length of time but can provide a temporary competitive advantage in the race to fish (Smith 1972, Ruttan 2001).

Organized private research activities in fishing industries have been minimal, and instead have largely consisted of adopting "off-the-shelf” innovations such as sonar, GPS, or the acoustic imaging technologies.

${ }^{15}$ The logistic growth function is $F\left(S_{t}\right)=r S_{t}\left[1-\frac{S_{t}}{K}\right]$.

${ }^{16}$ Technical progress that increases the intrinsic rate of growth, such as through genetic research or animal breeding, could be specified as $r(t)$ or more concretely as $r e^{\lambda t}$ (McAusland 2005).

${ }^{17}$ Murray (2007) makes this point through simulation. McAusland (2005) finds the same result.

${ }^{18}$ Remember that technical efficiency is equal to $e^{-\mu(t, Z)}$.

19 Stage II of Production for a classic production function occurs when there is a positive marginal product of an input over the input range between that corresponding to the maximum average product to the marginal product equal to zero. With the Schaefer yield-effort function, the average product of the single, composite input effort, $A P_{E}=Y / E$, as a ray from the origin, is found as effort approaches zero, and $M P_{E}>0$ for $0<E<E_{M S Y}$, where MSY denotes maximum sustainable yield. Moreover, $M P_{E}=0$ at $E_{M S Y}$ and $M P_{E}<0$ when $E>E_{M S Y}$. With an Allee effect, the lower bound occurs at the level of effort corresponding to the minimum viable population level. A depensatory growth function, which has an inflection point, allows the maximum $M P_{E}$ to occur before the maximum $A P_{E}$ as in the classic production case. With pure compensation growth, maximum $A P_{E}$ and maximum $M P_{E}$ coincide, differing slightly from the lower bound of Stage II.

$20 M P_{E}^{T E, t}>(<) 0$ when $E<(>) E_{M S Y}^{T E, t}$, which occurs on the upward (downward) sloping part of the yield-effort frontier in Figure 1.

${ }^{21}$ The rate of cost diminution overstates (understates) the rate of technical change if there exists decreasing (increasing) returns to size and exactly measures the rate of technical change only if there exist constant returns to size (Chambers 1988, p. 215). There are 
constant returns to size in $\mathrm{E}$ with the Graham-Schaefer production frontier since the production coefficient is 1 . Thus the primal and dual rates of technical progress are equal since $\partial \ln Y_{t} / \partial \ln E_{t}=\partial \ln C_{t} / \partial \ln Y_{t}=0$. Non-linear E leads to numerical solutions of the modified Golden Rule and a discrepancy between the rate of technical change and returns to size or scale.

${ }^{22}$ From Chambers, p. 227, Hicks neutrality, cost neutrality, and profit neutrality are the same phenomenon only when the technology is also homothetic (in our case it is linear homogeneous in $\mathrm{E}$, an even stronger condition). Cost neutrality means that optimal input ratios for either the cost minimizer or the profit maximizer are independent of the state of technology so long as output is held constant. (Chambers pp. 224-225) Profit-neutral technical change leaves profit-maximizing input ratios undisturbed (Chambers p. 224).

${ }^{23}$ This result also holds in steady-state equilibrium of the static model. Under open access, substitute from (15) to give $\partial^{2} T C / \partial S \partial t=\lambda Y P^{2} q e^{\lambda t-\mu(t)} / c>0$. A similar result holds for the static Pareto optimum of the sole owner.

${ }^{24}$ Since $M R_{E}=P M P_{E}$ for a constant $\mathrm{P}$, this is the same result found with $M P_{E}$.

${ }^{25}$ Technical inefficiency with the sole owner might be viewed as a regression in fishing skill or changes in fleet composition (with less technically efficient vessels), or less technically efficiency along the linear expansion path of the individual inputs comprising effort, given a state of technology and resource stock, compared to a previous time period.

${ }^{26}$ Second-order conditions are automatically satisfied with a quadratic function.

${ }^{27}$ This is a standard model. See, for example, Brown (2000), Clark (1990), Dasgupta (1982), Dasgupta and Heal (1979), or Hannesson (1993).

${ }^{28}$ The unit profit of harvest - the marginal value of the population - is an increasing function of $\mathrm{S}$, as in the traditional rule, but is now also an increasing function of $\lambda$, i.e. $\partial\left[p q S e^{\lambda t-\mu(t, z)}-c\right] / \partial S=p q e^{\lambda t-\mu(t, z)}>0$ and $\partial\left[p q S e^{\lambda t-\mu(t, z)}-c\right] / \partial t=\lambda p S q e^{\lambda t-\mu(t, z)}>0$.

${ }^{29}$ The specification of a linear cost function, $T C=c E$, in this standard textbook specification, which gives a cost function $T C=\left[c / e^{\lambda t-\mu(t, Z)}\right][Y / q S]$ that in turn leads to a Hamiltonian linear in the control variable $Y$, in part affects the interaction between the marginal stock effect and the marginal technology effect. A nonlinear cost specification allowing for increasing marginal costs in Y with diminished stock size could potentially and increasingly counter the marginal technology effect as stock sizes decline, through growing importance of the marginal stock effect relative to the marginal technology effect at low levels of resource abundance. We address this relationship in subsequent research, but note that the main results of this paper can be expected to hold but with a slower rate of resource stock decline and a higher resource stock level over an infinite time horizon in the limit case. 
${ }^{30}$ It depends in the traditional model on the relative size of the discount rate and the marginal stock effect. If the discount rate is lower than the marginal stock effect the optimal stock level is higher than MSY-level.

${ }^{31}$ Which it should be, because as time approaches infinity in Equation (41) the marginal stock effect and the marginal technical effect approach zero.

${ }^{32} \mathrm{We}$ are comparing the optimal yield paths in equilibrium. If the stock level is not in optimum, the solution is bang-bang or the most rapid approach, where the stock level is adjusted as quickly as possible to the equilibrium.

${ }^{33} S^{\infty}$ and $Y^{\infty}$ indicate the level of stock and yield respectively when time goes to infinity.

${ }^{34}$ Differentiate the unit cost with respect to time gives an expression whose sign depends on the relative size of $\dot{S} / S$ and $\lambda$. From equation (43) it can be seen that $\dot{S} / S$ is numerically less than $\lambda$.

${ }^{35}$ In reality, the ITQ policy is preferred by the fishermen instead of the tax policy, because the benefits of the ownership of the quotas go to the firm in the fishery when the ITQ system is implemented.

${ }^{36}$ The semi-parametric approach has an advantage over the stochastic frontier function in that misspecification of production dynamics is a basic problem that is seldom addressed in frontier models, and we were concerned with the construction of the generated composite effort variable and with serial correlation with a long time series of annual data. Moreover, econometric estimates are all heteroscedastic-consistent.

${ }^{37}$ With the Cobb-Douglas functional form, this specification is equivalent to that of Baltagi, Griffin, and Rich 1995). Intertemporal firm-specific technical efficiency and technical change effects can be obtained by using fitted values of the disturbance term $v_{i t}$ in $A_{i t}=A(t)+a_{i}+v_{i t}$ to obtain the index $T I_{i t}=e^{-A_{i t}}$, where changes in $A_{i t}$ imply percentage changes (Baltagi, Griffin, and Rich 1995).

${ }^{38}$ A chain index of technical change can be calculated as $T_{t}=T_{t-1}(\exp (A(t)-A(t-1)))$. For $\mathrm{t}=3, T_{4}=e^{0} \bullet e^{A(2)-0} \bullet e^{A(3)-A(2)} \bullet e^{A(4)-A(3)}=e^{0+A(2)+A(3)-A(2)+A(4)-A(3)}=e^{A(4)}$.

${ }^{39}$ Given weak separability of an input bundle, Fuss (1977, page 91, footnote 7) states, "Homotheticity is a necessary and sufficient condition for the validity of the two stage procedure. The further restriction of linear homogeneity is required to ensure that the product of the aggregate price and quantity indices equal total cost of the components." The latter corresponds to Fisher's factor reversal test. The index is not equal to a simple weighted average of the components unless the components are perfect substitutes or complements (Fuss 1977). 
${ }^{40}$ Resource stock is treated as exogenous in the production model because it was estimated by a Box-VPA model using Pacific-wide data on multiple gear types, so that considerable exogenous information (e.g. age structure of the population, length-weight relationships, recruitment, information from other nations, etc.) and exogenous assumptions about the population dynamics were the basis of the stock estimates rather than simply the catch and effort (days fished) data from a surplus production model for the North American Pacific coast for troll gear.

${ }^{41}$ The superlative Tornqvist index is not self-dual, and in that regard does not satisfy Fisher's factor-reversal test, but it does so only by a small order of approximation. Moreover, the direct quantity and indirect price forms $d o$ satisfy the factor-reversal test, and we are only concerned with the direct quantity index of effort. Moreover, we are not concerned with multilateral comparisons between the U.S. and Canada, and hence we calculate direct bilateral quantity indices for each country. Finally, the Tornqvist index, which provides a discrete approximation to the Divisia index, is based on a translog technology (Diewert 1976).

42 The index is subject to a base period normalization, such as all effort component quantities equal to unity (standard for quantity indices). Since the aggregate effort index is unique only up to a scalar multiple (since $\alpha+a_{i}$ cannot be identified from Equation (52)), $\alpha+a_{i}$ in Equation (52) is also set equal to unity. The effort aggregator function becomes equal to Equation (52) without $\alpha+a_{i}$, which is simply the normalized form of Equation (52) (Fuss 1977).

43 Implicitly, the capital stock is assumed to be in full static equilibrium. Moreover, since the aggregate effort index is unique only up to a scalar multiple, $\alpha$ in the effort aggregator function equals unity (Fuss 1977).

44 The Durbin-Watson value of 0.935098 indicates first-order serial correlation. The regression $\widehat{v}_{i t}=\rho \widehat{v}_{i t-1}+\eta_{i t}$, where $\widehat{v}_{i t}, \widehat{v}_{i t-1}$ are the current and lagged one-period residuals from Equation (50) and $\eta_{i t}$ is a random error, gave a t-ratio of 3.0518 for the null hypothesis $\theta=0$, providing confirming evidence of first-order serial correlation. The first observation was retained in the serial correlation correction.

${ }^{45}$ Allowing for technical change that is non-constant (giving the additional term $t^{2}$ ) or interacting with $E_{t}$ and/or $S_{t}$ (adding the terms $E_{t} t, S_{t} t$ ) and a full translog model, gave implausible and in some instances statistically insignificant results due to the introduced multicollinearity.

${ }^{46}$ The Durbin Watson value was 0.798669 . The regression $\widehat{v}_{i t}=\rho \widehat{v}_{i t-1}+\eta_{i t}$, where $\widehat{v}_{i t}, \widehat{v}_{i t-1}$ are the current and lagged one-period residuals from Equation (51) and $\eta_{i t}$ is a random error, gave a t-ratio of 11.9617 for the null hypothesis $\theta=0$, providing confirming evidence of first-order serial correlation. The first observation was retained in the serial correlation correction. 
${ }^{47}$ Industry experts confirmed this comparatively high rate of technical change as reasonable. The high rate is due to increased understanding of ocean conditions allowing forecasting of fish locations through temperature sensing devices reinforced by satellites, improvements in interpretation, and GPS, all of which give information about the overall distribution of albacore, dramatically reduces searching, and eases finding schools below the surface. Improved communications allows sharing of information among members of code groups, reducing search time, and increasing catch rates. Acoustic devices, such as sounders, are also increasingly sophisticated. The gear itself remained static. Improved weather forecasts extend the end of the fishing season.

${ }^{48}$ The Durbin Watson value was 0.117511 . The regression $\widehat{v}_{i t}=\rho \widehat{v}_{i t-1}+\eta_{i t}$, where $\widehat{v}_{i t}, \widehat{v}_{i t-1}$ are the current and lagged one-period residuals from Equation (51) and $\eta_{i t}$ is a random error, gave a t-ratio of 13.9036 for the null hypothesis $\theta=0$, providing confirming evidence of first-order serial correlation. The first observation was retained in the serial correlation correction. 